Atmos. Chem. Phys., 13, 10517-10534, 2013

www.atmos-chem-phys.net/13/10517/2013/

doi:10.5194/acp-13-10517-2013

(c) Author(s) 2013. CC Attribution 3.0 License.

\title{
Filamentary structure in chemical tracer distributions near the subtropical jet following a wave breaking event
}

\author{
J. Ungermann ${ }^{1,2}$, L. L. Pan ${ }^{2}$, C. Kalicinsky ${ }^{3}$, F. Olschewski ${ }^{3}$, P. Knieling ${ }^{3}$, J. Blank ${ }^{1}$, K. Weigel ${ }^{4}$, T. Guggenmoser ${ }^{1}$, \\ F. Stroh ${ }^{1}$, L. Hoffmann ${ }^{5}$, and M. Riese ${ }^{1}$ \\ ${ }^{1}$ Institute of Energy and Climate Research - Stratosphere (IEK-7), Research Centre Jülich GmbH, Jülich, Germany \\ ${ }^{2}$ National Center for Atmospheric Research, Boulder, Colorado, USA \\ ${ }^{3}$ Department of Physics, University of Wuppertal, Wuppertal, Germany \\ ${ }^{4}$ Institute of Environmental Physics (IUP), University of Bremen, Bremen, Germany \\ ${ }^{5}$ Jülich Supercomputing Centre, Research Centre Jülich GmbH, Jülich, Germany
}

Correspondence to: J. Ungermann (j.ungermann@fz-juelich.de)

Received: 29 October 2012 - Published in Atmos. Chem. Phys. Discuss.: 21 February 2013

Revised: 9 September 2013 - Accepted: 30 September 2013 - Published: 31 October 2013

\begin{abstract}
This paper presents a set of observations and analyses of trace gas cross sections in the extratropical upper troposphere/lower stratosphere (UTLS). The spatially highly resolved ( $\approx 0.5 \mathrm{~km}$ vertically and $12.5 \mathrm{~km}$ horizontally) cross sections of ozone $\left(\mathrm{O}_{3}\right)$, nitric acid $\left(\mathrm{HNO}_{3}\right)$, and peroxyacetyl nitrate (PAN), retrieved from the measurements of the CRISTA-NF infrared limb sounder flown on the Russian M55-Geophysica, revealed intricate layer structures in the region of the subtropical tropopause break. The chemical structure in this region shows an intertwined stratosphere and troposphere. The observed filaments in all discussed trace gases are of a spatial scale of less than $0.8 \mathrm{~km}$ vertically and about $200 \mathrm{~km}$ horizontally across the jet stream. Backward trajectory calculations confirm that the observed filaments are the result of a breaking Rossby wave in the preceding days. An analysis of the trace gas relationships between PAN and $\mathrm{O}_{3}$ identifies four distinct groups of air mass: polluted subtropical tropospheric air, clean tropical upper-tropospheric air, the lowermost stratospheric air, and air from the deep stratosphere. The tracer relationships further allow the identification of tropospheric, stratospheric, and the transitional air mass made of a mixture of UT and LS air. Mapping of these air mass types onto the geo-spatial location in the cross sections reveals a highly structured extratropical transition layer (ExTL). Finally, the ratio between the measured reactive nitrogen species $\left(\mathrm{HNO}_{3}+\mathrm{PAN}+\mathrm{ClONO}_{2}\right)$ and $\mathrm{O}_{3}$ is analysed to estimate the influence of tropospheric pollution on the extratropical UTLS.
\end{abstract}

In combination, these diagnostics provide the first example of a multi-species two-dimensional picture of the inhomogeneous distribution of chemical species within the UTLS region. Since Rossby wave breaking occurs frequently in the region of the tropopause break, these observed fine-scale filaments are likely ubiquitous in the region. The implications of the layered structure for chemistry and radiation need to be examined, and the representation of this structure in chemistry-climate models is discussed.

\section{Introduction}

The upper troposphere/lower stratosphere (UTLS) is a region significantly influenced by stratosphere-troposphere exchange (STE) (Holton et al., 1995). Changes in the composition of this region have the largest impact on radiative forcing (e.g. Solomon et al., 2007) and are major drivers for surface climate change (e.g. Riese et al., 2012).

The tropopause is thought to function as a barrier for trace gas exchange in the UTLS. There are a number of definitions for the tropopause, ranging from the thermal lapse-rate tropopause (WMO, 1957) to using certain values of potential vorticity (e.g. Danielsen, 1968). While these definitions agree rather well with one another at most times and places, large differences in tropopause identification are possible close to the subtropical jet (e.g. Hoerling et al., 1991; Holton et al., 1995; Kunz et al., 2011a). Breaking Rossby waves and 
tropopause folds are two dynamical mechanisms for STE that blur the boundary between troposphere and stratosphere. On the one hand, the subtropical jet provides a barrier for horizontal transport (e.g. Haynes et al., 2001), on the other hand, the baroclinic instabilities and wave breaking provide means for transport and isentropic mixing (e.g. Chen, 1995; Berthet et al., 2007), especially when the jet is weak (Postel and Hitchman, 1999).

Airborne limb sounders operated aboard research aircraft are one instrument type well suited for examining this region. These instruments have the capability of retrieving the volume mixing ratios (VMRs) of a wide range of trace gas species with high vertical resolution. For example, the limb scanning Cryogenic Infrared Spectrometers and Telescope for the Atmosphere - New Frontiers (CRISTA-NF; Kullmann et al., 2004) requires only about $70 \mathrm{~s}$ to acquire a full vertical profile with $0.25 \mathrm{~km}$ sampling, while newer models employing the limb imaging technique (Riese et al., 2005) are capable of acquiring multiple profiles with even better vertical sampling within a few seconds (e.g. Friedl-Vallon et al., 2006; Ungermann et al., 2011).

Airborne in situ measurements in the UTLS are highly accurate and precise but sketchy in the spatial domain, as they are limited to the flight path of the aircraft. In contrast to these locally sampling instruments, current spaceborne remote sensing instruments provide global coverage but offer only a limited spatial-temporal resolution. Further, the spaceborne instruments often suffer a reduced signal-tonoise ratio in the UTLS below $20 \mathrm{~km}$. For example, the Atmospheric Chemistry Experiment Fourier Transform Spectrometer (ACE-FTS; Bernath et al., 2005) offers a vertical resolution of sometimes down to $\approx 1 \mathrm{~km}$ for a wide range of species, but it cannot provide spatially coherent cross sections. Still, first studies of the ExTL (WMO, 2003) using ACE-FTS data have been successfully performed by Hegglin et al. (2009). In contrast, the High Resolution Dynamics Limb Sounder (HIRDLS; Gille et al., 2008) offers cross sections with a vertical resolution as low as $1.2 \mathrm{~km}$ in combination with a horizontal sampling of roughly $100 \mathrm{~km}$ for a comparatively limited set of species. HIRDLS cross sections were used by Pan et al. (2009) to identify large-scale tropospheric intrusions in the UTLS associated with a secondary tropopause. The Michelson Interferometer for Passive Atmospheric Sounding (MIPAS; Fischer et al., 2008) offers a coarser resolution than HIRDLS, but is capable of deriving more species. However, neither of these instruments provides a vertical resolution better than $1 \mathrm{~km}$ in combination with measuring closely spaced profiles. This puts the data taken by airborne limb sounders such as CRISTA-NF in a unique position to provide a bridge between the airborne in situ and the satellite remote sensing measurements.

This paper examines a snapshot of the extratropical UTLS around the subtropical jet observed on 29 July 2006 over the Mediterranean Sea by CRISTA-NF. For the first time, the layered chemical composition of the lowermost stratosphere

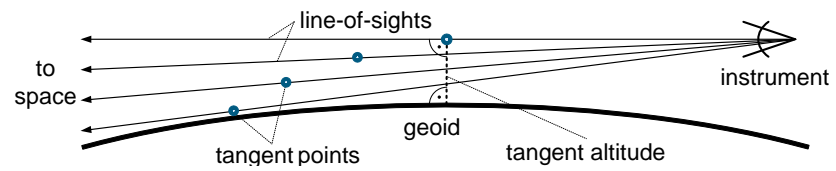

Fig. 1. A simple schematic of the measurement geometry of CRISTA-NF.

close to the subtropical jet is observed two-dimensionally at the resolution of vertically $\approx 0.5 \mathrm{~km}$ and horizontally $\approx 12.5 \mathrm{~km}$ (sampling along the flight-track) by an airborne infrared limb sounder. This paper improves upon work performed by Weigel et al. (2012), who evaluated a previous data version of the same flight with considerably less vertical resolution. As a result of an improved retrieval scheme, the cross sections exhibit a much improved vertical resolution for the stratospheric trace gases ozone and nitric acid (see Appendix A), which in turn allows for the identification of previously non-resolvable fine-scale filaments in the extratropical UTLS.

The trace gas cross sections show detailed filamentary structures, although the structures likely have a large extent orthogonal to the imaged plane. Backward-trajectories confirm that these filaments are the result of stirring induced by breaking Rossby waves during the preceding days. In this paper, stirring refers to the large-scale folding and dynamical deformation of air masses (e.g. McIntyre and Palmer, 1984), while mixing refers to change of chemical composition, within the scale of sampling, typically due to turbulent mixing. The state of mixing between UT and LS air in the filaments can be identified by the location of air parcels in tracer-tracer space. Mapping the tracer-tracer-space locations of air parcels to the geo-spatial space allows visualising the dynamical and chemical characteristics of the UTLS.

Two of the retrieved trace gas species are reactive nitrogen species. These can be used to derive a crude estimate of the total reactive nitrogen. The ratio between this estimate and the measured $\mathrm{O}_{3}$ VMRs can serve as a simple indicator of polluted air.

\section{Measurements and model data}

This paper is based largely on remote sensing measurements taken by CRISTA-NF during a test-flight for the African Monsoon Multidisciplinary Analysis (AMMA; see Cairo et al., 2010, and references therein) campaign and auxiliary global meteorological analyses data.

CRISTA-NF is a liquid-helium-cooled, infrared limb sounder with a high signal-to-noise ratio and a high measurement speed, taking one spectrum in $1.2 \mathrm{~s}$. For a vertical profile, one spectrum is taken every $\approx 0.25 \mathrm{~km}$, leading to an altitude profile of 60 measurements every $\approx 70$ s (see Fig. 1). This yields roughly $12.5 \mathrm{~km}$ horizontal distance between profiles for a typical speed of the aircraft. The resolution along 


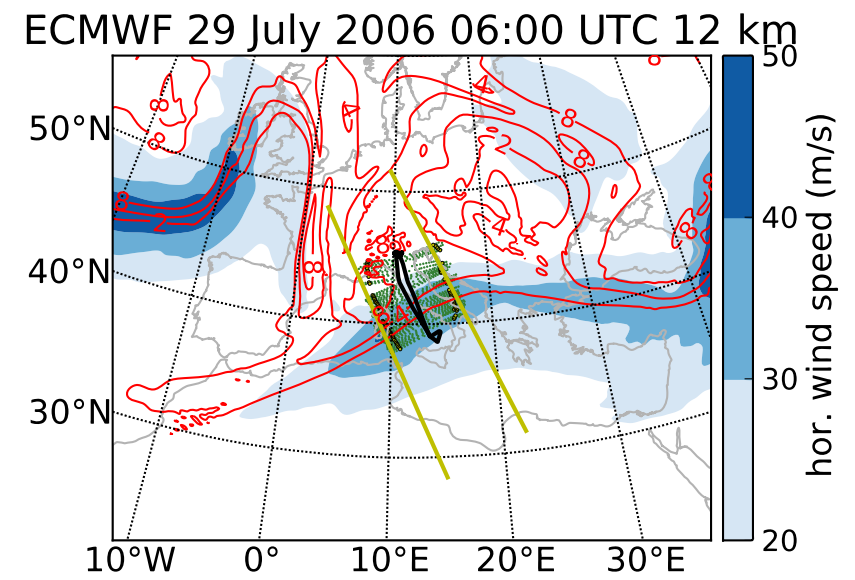

Fig. 2. Overview of aircraft flight path and meteorological situation on 29 July 2006 06:00 UTC at $12 \mathrm{~km}$ altitude. Shown as blue surfaces are horizontal wind speeds. Shown as red contours are potential vorticity in PVU. The thick black line shows the flight path of M55-Geophysica. The horizontal position of every fourth tangent point of radiance measurements is shown as a small green circle. Yellow dots highlight tangent points closest to $12 \mathrm{~km}$ altitude. The two yellow lines indicate the horizontal position of two vertical cross sections depicted in Fig. 3.

the line-of-sight is between $\approx 200$ and $300 \mathrm{~km}$, depending on the observed altitude. The optical system of CRISTANF consists of the centre telescope and two grating spectrometers of the Space Shuttle experiment CRISTA that was successfully flown on the Shuttle Pallet Satellite (SPAS) in November 1994 (STS 66) and August 1997 (STS 85) (Offermann et al., 1999; Grossmann et al., 2002). CRISTA-NF employs 15 detectors for different wavelength regions, but for technical reasons only one operating in the wavenumber range from 776.0 to $868.0 \mathrm{~cm}^{-1}$ is used here. A detailed discussion of the instrument calibration is given by Schroeder et al. (2009). The instrument was deployed on board the high flying (up to $20 \mathrm{~km}$ for the discussed flight) Russian research aircraft M55-Geophysica viewing starboard.

Spatially highly resolved trace gas VMRs are determined from the spectrally resolved infrared radiance measurements. The given CRISTA-NF measurements allow for the derivation of VMRs for the trace gas species of peroxyacetyl nitrate (PAN), nitric acid $\left(\mathrm{HNO}_{3}\right)$, and ozone $\left(\mathrm{O}_{3}\right)$. Water vapour $\left(\mathrm{H}_{2} \mathrm{O}\right)$ and trichlorofluoromethane (CFC-11) were also retrieved with high quality, but the contrast in VMRs between predominantly upper tropical tropospheric and predominantly lowermost stratospheric air masses was much smaller than for the discussed species and thus less expressive. The retrieval process is summarised in Appendix A.

For analysis of the meteorological setting and also as input for the retrieval, operational analysis data supplied by the European Centre for Medium-range Weather Forecast (ECMWF) were used. For the given day of 29 July 2006, the analysis is available in six-hour time steps in the T799/L91 resolution, which corresponds to a horizontal resolution of $\approx 0.2^{\circ} \times 0.2^{\circ}$ with 91 levels between the surface and $80 \mathrm{~km}$.

For the trajectory studies presented in Sect. 3.3, the trajectory model TRAJ3D (Bowman, 1993; Bowman and Carrie, 2002) was used. The model is driven by winds from the Global Forecast System (GFS) final gridded analysis data sets (FNL) provided by the National Centers for Environmental Prediction (NCEP). These winds are available in sixhour time steps on a global grid of horizontally $\approx 1.0^{\circ} \times 1.0^{\circ}$ with 26 pressure levels between 1000 and $10 \mathrm{hPa}$.

\section{Analysis}

\subsection{A research flight following a breaking Rossby wave}

The research flight discussed in this paper took place over Italy on 29 July 2006. The flight path of the M55-Geophysica is shown in Fig. 2. The ECMWF data presented in this figure show the meteorological setting on 29 July 2006, 06:00 UTC shortly before the actual flight. The aircraft took off in Verona at 06:54 UTC heading south-southeast towards the jet stream. The position of the jet stream can be roughly determined from horizontal wind speeds larger than $\approx 20 \mathrm{~m} \mathrm{~s}^{-1}$ at $12 \mathrm{~km}$ altitude in Fig. 2. The CRISTA-NF instrument was viewing westwards during this portion of the flight. The tangent points illustrate roughly the geographic location of measured air masses. At 07:30 UTC, the aircraft began a dive and performed a U-turn before heading back towards Verona at 08:00 UTC. During the following northbound leg of the flight, CRISTA-NF measured air masses east of the flight track. The flight path orthogonally crossed the 2 and 4 PVU contour lines that mark the approximate horizontal position of the transition region between the troposphere and the stratosphere at $12 \mathrm{~km}$. This enabled CRISTA-NF to measure along comparably homogeneous air masses (as they are of similar potential vorticity), thereby reducing potential artefacts induced by large gradients in temperature or trace gas VMRs along the line-of-sight of the instrument.

The distribution of wind speeds indicates a break of the jet stream during a wave breaking event. The position of the 2 PVU line follows roughly the position of the jet stream before the wave breaking took place, which left a long-drawn filament of partly stratospheric air towards the west. The large area of potential vorticity between 2 and 4 PVU east of the flight track is a remnant of an earlier poleward wave breaking event, where a large portion of the jet stream was also cut off.

Figure 3 shows two vertical cross sections through the ECMWF data set of 29 July 2006, 06:00 UTC that are representative for the two cross sections measured by CRISTANF. Due to the 3-D location of measurements in space and to the horizontal averaging, no simple vertical cross section through ECMWF data can be representative for the full altitude range of measurements. The ECMWF cross sections 

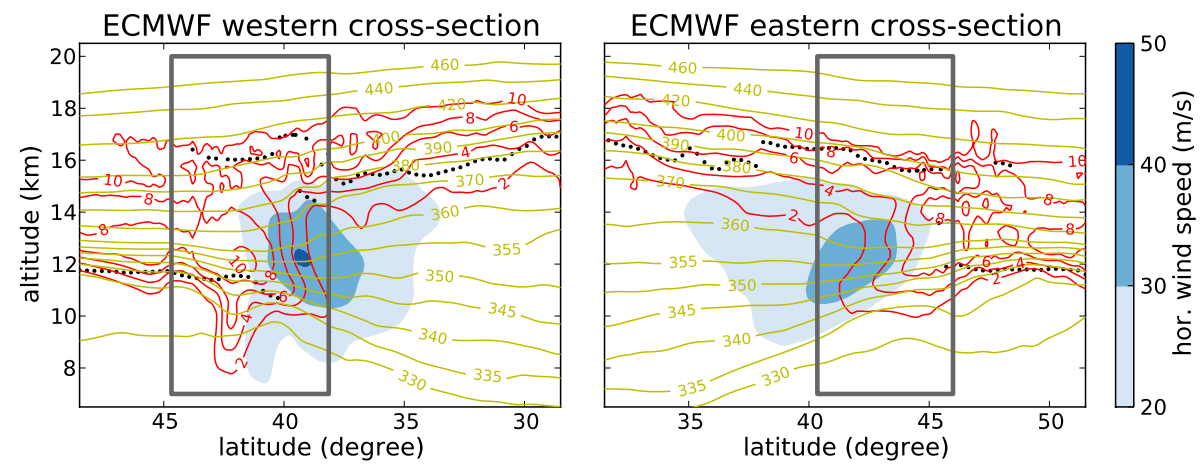

Fig. 3. Overview of meteorological situation on 29 July 2006 06:00 UTC. Depicted are two vertical cross sections, the horizontal positions of which are indicated as yellow lines in Fig. 2. Blue surfaces show horizontal wind speed. Red contours show potential vorticity in PVU. Yellow contours indicate potential temperature in Kelvin. Black dots indicate the position of primary and secondary lapse-rate tropopause. The dark grey rectangle indicates the approximate position of the measured trace gas cross sections presented later on.

are positioned horizontally to be most representative for the measurements taken at $12 \mathrm{~km}$ altitude. Further, there is also a varying time delay of up to three hours between the data points of the retrieved cross section and the model data provided by ECMWF. The region of sampling is under double tropopause conditions during the flight period, as indicated in the figure. The primary and secondary tropopause levels shown in the figure are derived using the ECMWF temperature profiles.

In both the western and the eastern cross section, the potential vorticity field identifies a tropopause fold, where stratospheric air intrudes along a baroclinic structure below the jet stream into the troposphere. The tropical tropopause (here at 16 to $17 \mathrm{~km}$ altitude) continues several hundred kilometres northward over this intrusion. Lower potential vorticity values just below this secondary tropopause further suggest a small tropospheric intrusion into the stratosphere just above the jet stream (see also Sect. 3.2). This is consistent with work of Pan et al. (2009) and Homeyer et al. (2011) associating a double tropopause with such intrusions. Further, the observed region is known to be a place where the tropical tropopause is often extended northwards during summer due to the influence of the monsoon circulation (e.g. Chen, 1995; Dunkerton, 1995). The potential vorticity in the lowermost stratosphere below $16 \mathrm{~km}$ on the subtropical side of the jet stream also shows a very inhomogeneous structure. In the western cross section, a further intrusion of stratospheric air can be seen around $42^{\circ} \mathrm{N}$, where the $6 \mathrm{PVU}$ contour line extends well below the primary tropopause down to $10 \mathrm{~km}$.

The potential temperature structure of the cross section shows typical characteristics of the subtropical transition. The 330-360 K isentropes show upward/downward inclinations above/below the jet core level, marked by the $355 \mathrm{~K}$ isentrope, as the flight moving equatorward across the jet. Although these are well known structures, we point it out to connect to the tracer structure shown later.

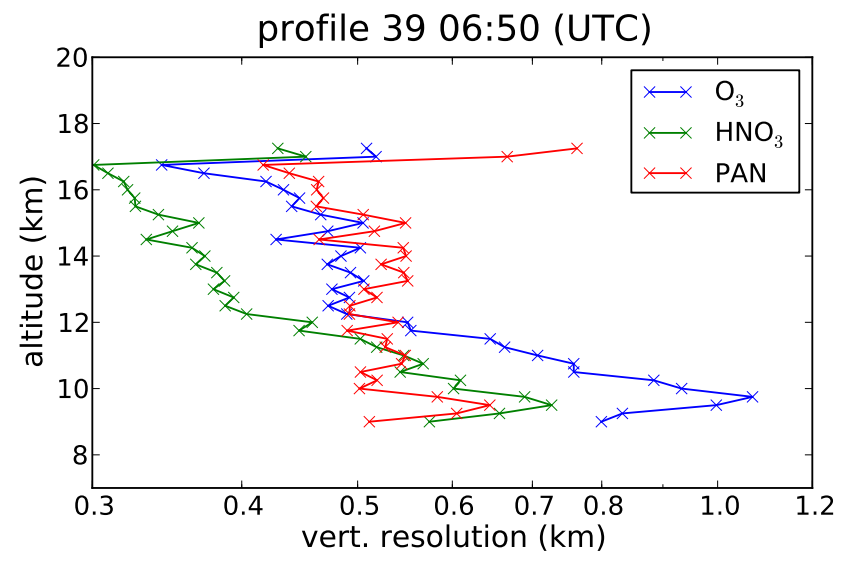

Fig. 4. Vertical resolution for retrieved $\mathrm{O}_{3}, \mathrm{HNO}_{3}$, and PAN VMRs for a representative profile of the western cross section.

There were few clouds seen during the flight above $8 \mathrm{~km}$ and all parcels, for which trace gas VMRs are derived, are cloud free.

\subsection{Filamentary structure in observed trace gases}

This section presents derived trace gas VMRs for $\mathrm{O}_{3}, \mathrm{HNO}_{3}$, and PAN. Linearly derived precision and accuracy figures for the discussed species are given in Table 1; comparisons with measurements by other in situ and remote sensing instruments has ascertained the validity of these figures for a different research flight (see Ungermann et al., 2012). The vertical resolution is shown for an exemplary profile in Fig. 4. Note the excellent vertical resolution of $\mathrm{HNO}_{3}$, which is down to $0.3 \mathrm{~km}$ near the flight level. The vertical resolution deteriorates towards lower altitudes due to a decreasing signal-tonoise ratio caused by lower VMRs for $\mathrm{O}_{3}$ and $\mathrm{HNO}_{3}$ and generally stronger emissions by more abundant interfering species at lower altitudes. 

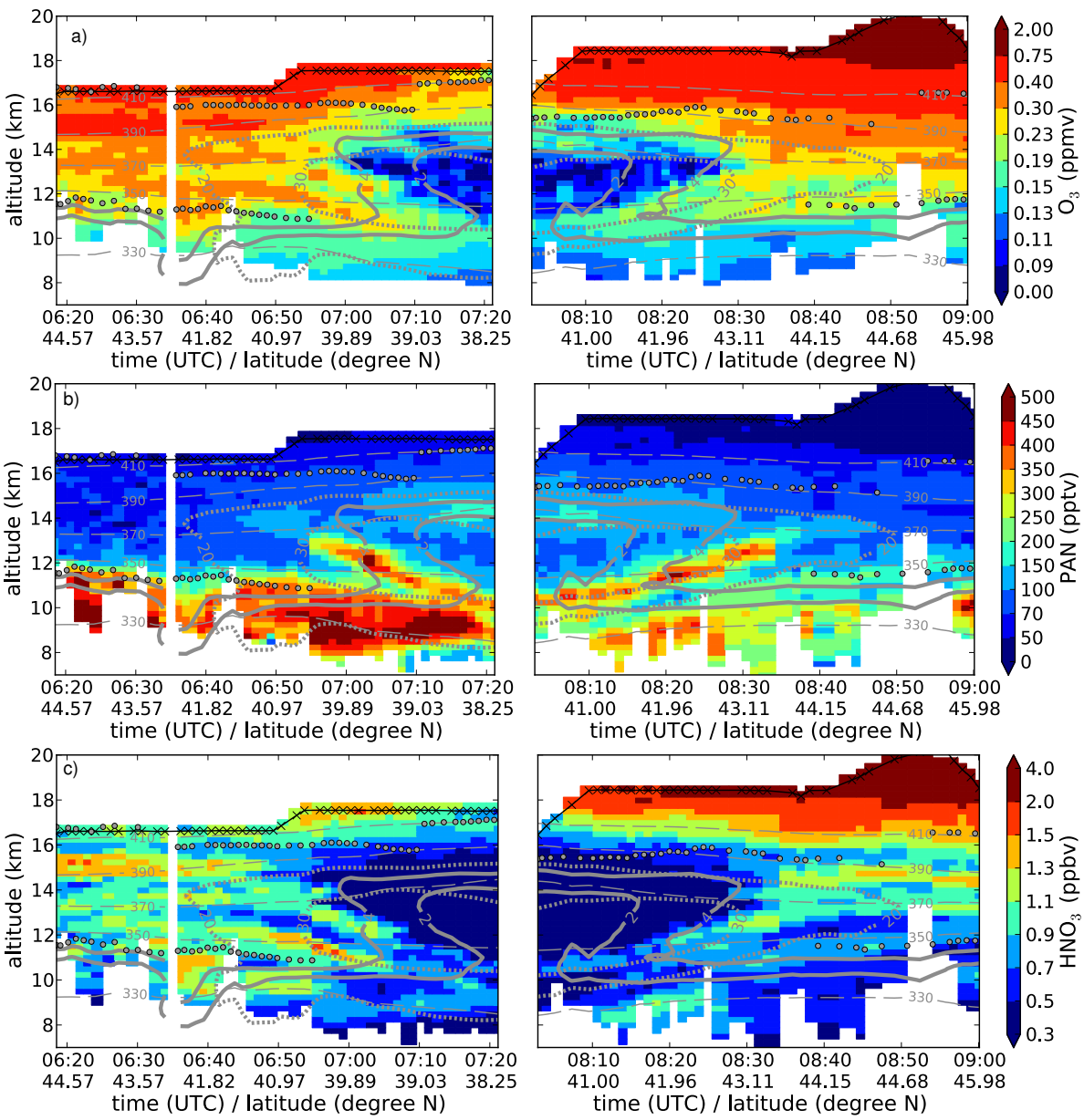

Fig. 5. Retrieved cross sections of $\mathrm{O}_{3}(\mathbf{a})$, $\mathrm{PAN}$ (b), and $\mathrm{HNO}_{3}$ (c). The left cross section shows the result of the westward pointing measurements and the right cross section shows correspondingly the result of the eastward pointing measurements. Retrieved volume mixing ratios are depicted as coloured boxes. A discrete, non-linear colour scale was chosen to better highlight filamentary structures. The abscissa shows time of measurement and latitude at $12 \mathrm{~km}$ altitude. The altitude of M55-Geophysica at the time of measurement is indicated as a solid black line with crosses marking the time of successfully measured profiles. The position of primary and secondary lapse-rate tropopause are indicated by thick grey dots. The dotted grey lines show horizontal ECMWF wind speeds of 20 and $30 \mathrm{~m} \mathrm{~s}^{-1}$. The thick solid grey contour lines show ECMWF potential vorticity of 2 and 4 PVU. The thin dashed grey contour lines shows ECMWF isentropes. To generate the contours, the ECMWF model data were interpolated temporally and spatially to the horizontally closest tangent point. The white gap at 06:35 UTC marks a change in heading of the aircraft by $16^{\circ}$ where a profile was lost.

Table 1. Approximate precision and accuracy for discussed species as derived by linear diagnostics (Rodgers, 2000). The first number refers to values retrieved at instrument altitude, while the second number refers to values at altitudes $\approx 8 \mathrm{~km}$ below the instrument.

\begin{tabular}{lll}
\hline species & precision & accuracy \\
\hline $\mathrm{O}_{3}$ & $40 / 20 \mathrm{ppbv}$ & $40 / 40 \mathrm{ppbv}$ \\
$\mathrm{PAN}$ & $10 / 20 \mathrm{pptv}$ & $20 / 20 \mathrm{pptv}$ \\
$\mathrm{HNO}_{3}$ & $0.2 / 0.1 \mathrm{ppbv}$ & $0.1 / 0.1 \mathrm{ppbv}$ \\
\hline
\end{tabular}

Figure 5a shows two cross sections of $\mathrm{O}_{3}$ VMRs. Trace gas VMRs above the flight level are not shown as they cannot be retrieved with a similar spatial resolution to those be- low. The presence of clouds limits the retrieval at lower altitudes. Retrieved temperature is used to derive primary and secondary thermal lapse-rate tropopause locations. ECMWF model data have been spatially (to the location of the closest tangent point) and temporally (to the time of measurement) interpolated onto the retrieved cross sections to provide further ancillary data. Accordingly, the positions of the 2 and 4 PVU potential vorticity surfaces, horizontal wind speeds of 20 and $30 \mathrm{~m} \mathrm{~s}^{-1}$, and selected isentropes are shown.

The distribution of potential vorticity in Fig. 2 suggests roughly homogeneous conditions along the line-of-sight for the measurements after 06:40 UTC below $16 \mathrm{~km}$. However, the measurements taken before 06:40 UTC might be affected 
by gradients of temperature and trace gas VMRs along the line-of-sight, especially at altitudes below $\approx 15 \mathrm{~km}$.

The western cross section of $\mathrm{O}_{3}$ in Fig. 5a shows several thin filamentary structures. Several tongues of stratospheric air penetrate the subtropical jet stream. One longdrawn filament at $12 \mathrm{~km}$ altitude extends in a tropopause fold down to $\approx 10 \mathrm{~km}$; the vertical extent of this filament is $\approx 0.8 \mathrm{~km}$. A second filament with increased $\mathrm{O}_{3}$ VMRs is located above, separated by a $\approx 0.5 \mathrm{~km}$ thin layer of air with reduced $\mathrm{O}_{3}$ VMRs. This second $\mathrm{O}_{3}$ filament is located at $13.5 \mathrm{~km}$ altitude on the subtropical side of the jet stream and extends down to $12 \mathrm{~km}$ on the tropical side. A very small third tongue is located at $14 \mathrm{~km}$ altitude at 06:55 UTC and a fourth filament is positioned right below the tropopause between 07:00 UTC and 07:10 UTC. On the subtropical side, a thin layer of reduced ozone VMR is visible just below the secondary tropopause suggesting an intrusion of tropospheric air that is consistent with reduced potential vorticity values in Fig. 3. The ozone VMRs below the subtropical tropopause (here at 10 to $12 \mathrm{~km}$ altitude) are elevated to $\approx 150 \mathrm{ppbv}$, presumably due to a combination of photochemical production in polluted air (see also $\mathrm{HNO}_{3}$ and PAN VMRs below) and mixing with stratospheric air. More typical background $\mathrm{O}_{3}$ values for this altitude range are on the order of 50 to 100 ppbv (e.g. Murphy et al., 1993; Pan et al., 2007).

The eastern cross section provides a simpler picture, with overall reduced $\mathrm{O}_{3}$ VMRs below $14 \mathrm{~km}$. Still, two filaments similar to the lower two filaments of the western cross section of elevated $\mathrm{O}_{3}$ VMRs can be discerned that extend deep into the tropopause fold: a rather weak filament located just above the subtropical tropopause and a more pronounced filament starting at $13.5 \mathrm{~km}$ and extending down to $11 \mathrm{~km}$ on the anticyclonic side.

Both PAN cross sections in Fig. 5b show high PAN VMRs below the subtropical tropopause greater than $\approx 400$ pptv. Both cross sections show a filament with high PAN content of above $300 \mathrm{pptv}$ extending from about $13 \mathrm{~km}$ down to $10 \mathrm{~km}$. The filament extends even up to $14 \mathrm{~km}$, but with reduced VMRs of only 100 pptv. This filament nearly coincides with the upper edge of elevated $\mathrm{O}_{3}$ VMRs inside the jet stream; however, especially the lower portion seems to be located $\approx 250 \mathrm{~m}$ lower. The highest VMRs occupy only one or two pixels vertically indicating a vertical extent of $\approx 0.5 \mathrm{~km}$.

This filament seems to be not isentropic but covers instead a range of potential temperature from $365 \mathrm{~K}$ for the highest altitude with a VMR of 300 pptv down to $335 \mathrm{~K}$. Several factors may contribute to this discrepancy. First, both the intrusion of PAN into the stratosphere as also the further development of the filamentary structure along the baroclinic jet stream may have been non-adiabatic. The tracer structure may be capturing small-scale processes that are not represented in the ECMWF analysis. An example for such a process are gravity waves from jet dynamics, as described in Zhang (2004). The pointing of the CRISTA-NF instru- ment during the flight would not have allowed for the direct detection of such gravity waves, e.g. in retrieved temperature. Second, the ECMWF temperature model data may be mis-aligned in time and space with the actual physical structure; further artefacts might be introduced by the linear interpolation in time of the available model data. Last, the derived trace gas VMRs represent a complicated weighted mean along the line-of-sight of the instrument, being slightly different for each derived quantity, causing further misalignment with the ECMWF temperature data sampled at tangent point locations.

The measured PAN VMRs of 50 to $70 \mathrm{pptv}$ in the lowermost stratosphere are consistent with VMRs derived by Glatthor et al. (2007) from MIPAS measurements. Elevated PAN VMRs in the upper UTLS are probably caused by mixing with tropospheric air, which is supported by the close spatial proximity of air masses of PAN VMRs above $70 \mathrm{pptv}$ to the tropical troposphere. According to Singh et al. (2007), a PAN VMR of $600 \mathrm{pptv}$ below the subtropical tropopause is typical for polluted air masses.

The cross sections in Fig. $5 c$ depict $\mathrm{HNO}_{3}$ VMRs. The western cross section shows again the more layered structure. Two $\mathrm{HNO}_{3}$ filaments coincide with the lower two $\mathrm{O}_{3}$ filaments. The lowest filament even seems to extend down to $9.5 \mathrm{~km}$ around $07: 20 \mathrm{UTC}$, but with VMRs so much decreased that it cannot be readily distinguished from the polluted air found elsewhere in this altitude range. Both filaments continue horizontally northwards at least up to the profile measured at 06:35 UTC, where a change of the aircraft heading causes a gap in the cross section. The filament with reduced $\mathrm{HNO}_{3}$ VMRs in between is likely tropospherically influenced, which is also supported by elevated CFC-11 VMRs (by 5 to 10 pptv compared to air masses above and below; not depicted).

At 06:38 UTC and $11 \mathrm{~km}$ altitude, an intrusion of stratospheric air below the tropopause is suggested by increased $\mathrm{HNO}_{3}$ VMRs and decreased PAN VMRs (see also Fig. 5b). This intrusion is consistent with potential vorticity derived from ECMWF data.

The major features of the $\mathrm{HNO}_{3}$ western cross section can be found again in the eastern one, albeit mostly several hundred meters lower and with less steep gradients. The elevated $\mathrm{HNO}_{3}$ VMRs around $8.5 \mathrm{~km}$ nearly coincide again with elevated PAN VMRs, with $\mathrm{HNO}_{3}$ VMR maxima being located $\approx 250 \mathrm{~m}$ above the PAN VMR maxima.

These cross sections demonstrate a very complex structure of the transition region between the troposphere and the stratosphere close to the subtropical jet. The UTLS shows a very inhomogeneous picture consisting of several layers with a vertical extent smaller than $0.8 \mathrm{~km}$ and a horizontal extent of several hundred $\mathrm{km}$. Within the jet stream, these filaments are inclined towards the troposphere but do not follow isentropes, instead covering up to $30 \mathrm{~K}$ of potential temperature between highest and lowest part. Many of these filaments also cross the potential vorticity contours almost 
perpendicularly, implying that these air masses should not be trivially assigned to tropospheric or stratospheric origin according to their potential vorticity value. This suggests the work of non-conserving processes that modify both the entropy and the potential vorticity of the filaments. Except for the stratospheric intrusion around 06:38 UTC, the primary tropopause seems to clearly separate air masses. Close to the jet stream the temperature structure breaks down (between 06:55 UTC and 07:15 UTC and between 08:20 UTC and 08:40 UTC) and no thermal tropopause is detected at $\approx 11 \mathrm{~km}$, even though the vertical gradients in all shown trace gases suggest a vertical boundary.

\subsection{Wave breaking induced genesis of the observed filamentary structure}

This section presents a backward trajectory analysis connecting the filamentary structure to the transport history of the air mass involved. Backward trajectories were calculated for the air masses sampled by the western cross section using NCEP-GFS wind fields. As $\mathrm{HNO}_{3}$ VMRs show the most obvious filamentary structure, positive $\mathrm{HNO}_{3}$ anomalies near the jet stream are used to select air parcels with predominantly stratospheric origin. The corresponding trajectories show three dominant air streams. Further, a set of air parcels with high PAN VMRs close to the jet stream around $10 \mathrm{~km}$ altitude was added, as this is the region where the maxima of PAN VMRs do not perfectly coincide with the maxima of the $\mathrm{HNO}_{3}$ filament. Thus, these air parcels may show the best connection to the tropospheric origin of PAN. The position of these four air streams, arriving in the western cross section on the final day, are shown as coloured circles in Fig. 6. To simplify the description, these sets of air parcels are referred to by their relative mean vertical position surrounded by quotation marks and the employed colour in brackets in the following, e.g., as the "high-stratospheric (red)" filament. Four different air streams are identified:

- the "high-stratospheric (red)" filament,

- the "middle-stratospheric (green)" filament,

- the "low-stratospheric (blue)" filament, and the

- the "tropospheric (black)" filament.

The "high-stratospheric (red)" and "high-stratospheric (green)" filament are selected to represent the filament with $\mathrm{HNO}_{3}$ enhancement and lie mostly within the lower stratosphere poleward of the jet. The "low-stratospheric (blue)" filament is selected to represent the $\mathrm{HNO}_{3}$ enhanced air mass below the tropopause and is associated with the stratospheric intrusion. Last, the "tropospheric (black)" filament is selected because this airmass of elevated PAN VMRs may give insight into the tropospheric sources of the PAN content of the more stratospheric filaments.

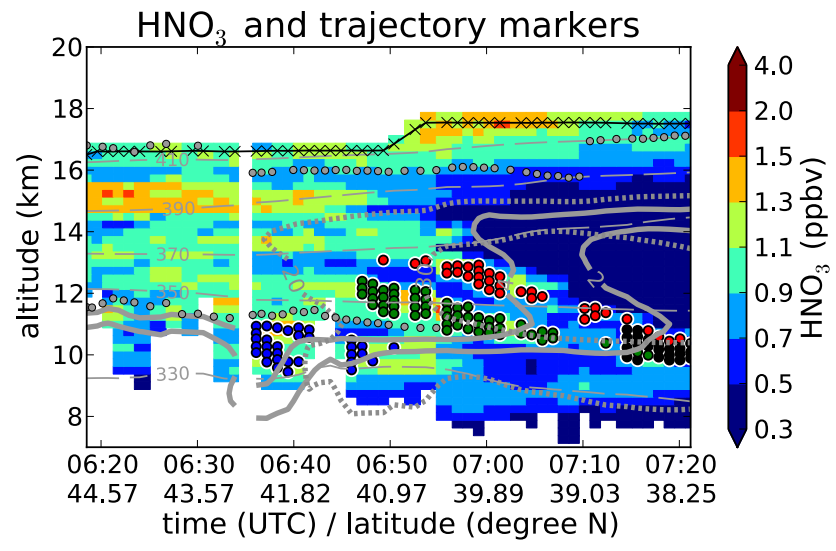

Fig. 6. Western cross section of $\mathrm{HNO}_{3}$ including markers of selected air parcels. The red, green, blue and black circles mark the position of air parcels examined in the backward-trajectory simulations.

According to the backward trajectory simulations, the high $\mathrm{HNO}_{3}$ VMRs of greater than $0.9 \mathrm{ppbv}$ in the upper troposphere of the western cross section are decidedly of tropospheric origin. These specific air parcels can be traced back to the Iberian peninsula. The trajectory studies suggest that the source region of the other polluted tropospheric air parcels is in North America.

Figure 7 shows the horizontal and vertical movements of the selected sets of air parcels. The "tropospheric (black)" air stream contains several air parcels that were uplifted over the Atlantic Ocean close to the east coast of North America, possibly by a warm conveyor belt (e.g. Stohl, 2001), to $\approx 12 \mathrm{~km}$ altitude and were then transported on the subtropical side of the jet stream towards Europe. While all tracked air parcels perform a downward movement during the two preceding days, the vertical range (both in potential temperature and altitude) remains rather stable up to 25 July 2006.

The genesis of the situation becomes more clear in Fig. 8 that shows the horizontal position of the air parcels marked in Fig. 6 in the same colours for four progressing time steps, each $36 \mathrm{~h}$ apart. The last figure corresponds to the position and situation shortly before the research flight. The meteorological setting during the shown time frame is dominated by a cyclone in the North Atlantic on the one hand and a (weakening) anti-cyclone around $35^{\circ} \mathrm{N}$ on the other hand. In combination, they largely determine the flow of the air parcels and the jet stream.

The breaking Rossby wave in the jet stream brings the four different air streams together by means of differential advection. As the air parcels are of different origin in space and time, their chemical composition was originally also different. The "high-stratospheric (red)" filament especially changes its originally stratospheric chemical composition by mixing with polluted tropospheric air. The trajectories cannot fully capture this process as they only simulate advection and 


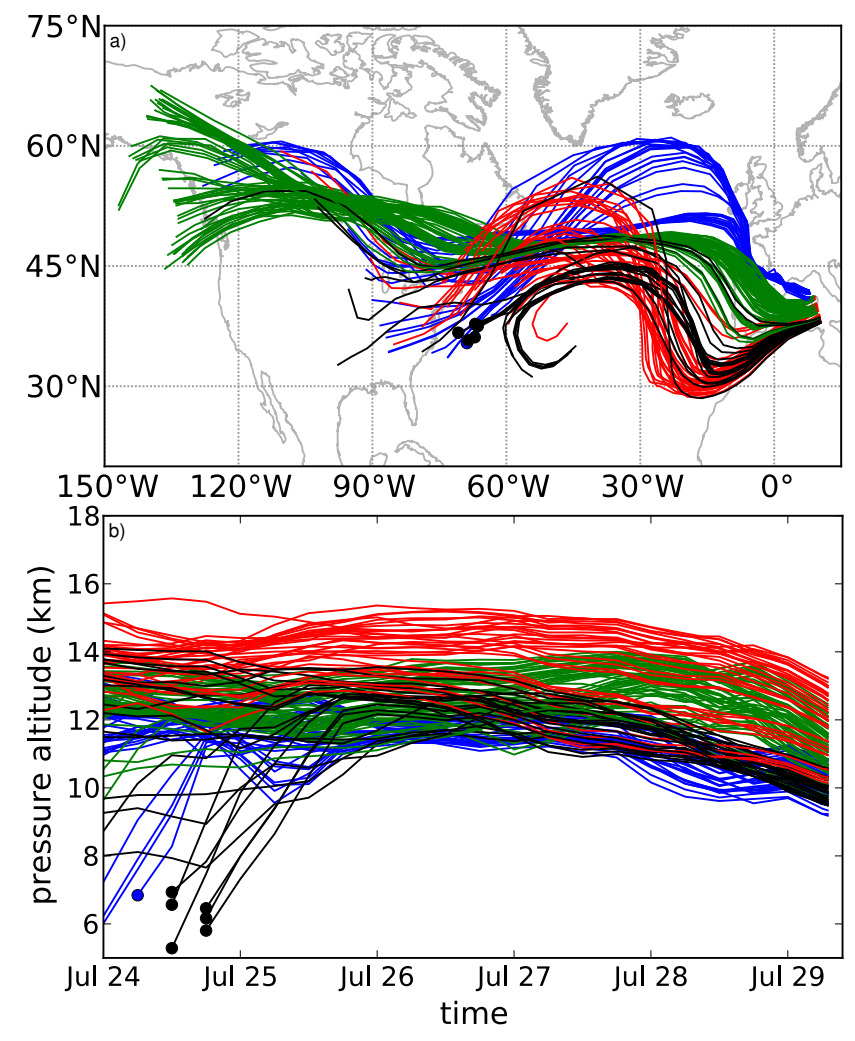

Fig. 7. Backward-trajectories of four groups of selected air parcels. (a) and (b) show the horizontal and vertical course of the trajectories, respectively, for the five days preceding the measurement. The backward trajectory is terminated, if the parcel "sinks" below $7 \mathrm{~km}$, whereby this last position is marked by a coloured dot. See also Fig. 6.

not mixing. However, the origin of the "tropospheric (black)" air parcels close to the lower half of the "high-stratospheric (red)" filament suggests strongly that the PAN found in the "high-stratospheric (red)" filament has the same source region.

From Fig. 8, it is evident that all three sets of stratospheric air parcels have been part of the core of the subtropical jet at some point in time, but were differently advected by the breaking Rossby wave to finally arrive at the same destination. As the signatures of tropospheric and stratospheric gases is much weaker for the eastern than for the western cross section, this suggests that these filaments do not extend much further than the horizontal position of the eastern cross section. In combination with the distribution of potential vorticity, the horizontal extent of the filaments along the jet stream should thus be smaller than $\approx 15^{\circ}$ of longitude or $\approx 1100 \mathrm{~km}$.

Combining the results obtained from meteorological data with the CRISTA-NF measurements of vertical and horizontal extent across the jet stream, the filaments cover a volume of roughly $1100 \times 200 \times 0.8 \mathrm{~km}^{3}$. All three predominantly stratospheric filaments are entangled in between air masses with significant tropospheric characteristics that were folded in during the breaking of the last baroclinic wave. The timescale involved in these stirring processes is rather short and numbers only a few days. By repeated folding, a very inhomogeneous structure with filaments of less than $0.8 \mathrm{~km}$ thickness is created.

\subsection{Mixing and filaments in the extratropical transition layer}

Trajectory analyses presented in the previous section indicate that the filamentary structure is created by large-scale dynamical processes including Rossby wave breaking. The trajectory calculations, however, are only representing advection by the wind field. The formation of the observed structure involves both advection and mixing (e.g. Konopka and Pan, 2012). In this case, small-scale processes such as turbulent mixing induced by the shear and strain in the flow, are also expected to contribute to the observed structure, which can be diagnosed using tracer-tracer relationships. Thus, this section explores the chemical characteristics of the observed trace gas structure using tracer-tracer relationships. This analysis aims to project the information gained in chemical tracer-tracer space to geo-spatial space. As a result, a highly resolved two-dimensional geo-spatial picture of the UTLS composition near the tropopause break reveals the accumulative effect of advection and mixing of stratospheric and tropospheric air.

Our analyses focus on the tracer-tracer relationship between $\mathrm{O}_{3}$ and PAN, i.e., using $\mathrm{O}_{3}$ as the stratospheric tracer and PAN as the tropospheric tracer. $\mathrm{O}_{3}$ is the most frequently used stratospheric tracer. (e.g. Hoor et al., 2002; Pan et al., 2004). Using the flight data, $175 \mathrm{ppbv}$ is used as a critical value to separate the stratospheric and tropospheric air mass. This threshold is higher than the typical 60 to $100 \mathrm{ppbv}$ used in previous studies (compare Singh et al., 2007; Pan et al., 2007). This empirical threshold is based on the $\mathrm{O}_{3}$ distribution in the sampling region from the retrieval. This higher value may be a combination of UT ozone retrieval uncertainty (see Table 1) and pollution in the sampled airmass.

As a tropospheric tracer, PAN has some different characteristics from the frequently used compounds such as $\mathrm{CO}$ and $\mathrm{H}_{2} \mathrm{O}$. As a secondary pollutant, its sources are biomass burning and anthropogenic pollution in the troposphere (Stephens, 1969). Its lifetime is comparatively short, ranging from seconds in the lower troposphere to days and months in the uppermost troposphere (e.g. Roberts, 1990). 80 pptv of PAN were chosen as the threshold for stratospheric air, i.e., air parcels with less than 80 pptv are considered to be chemically stratospheric.

As discussed in previous work, the tracer-tracer relationship in the UTLS for a stratospheric and tropospheric tracer pair is approximately an "L" shape (e.g. Hintsa et al., 1998; Hoor et al., 2002; Pan et al., 2007). The generally compact relationship is from the significantly different ranges of 

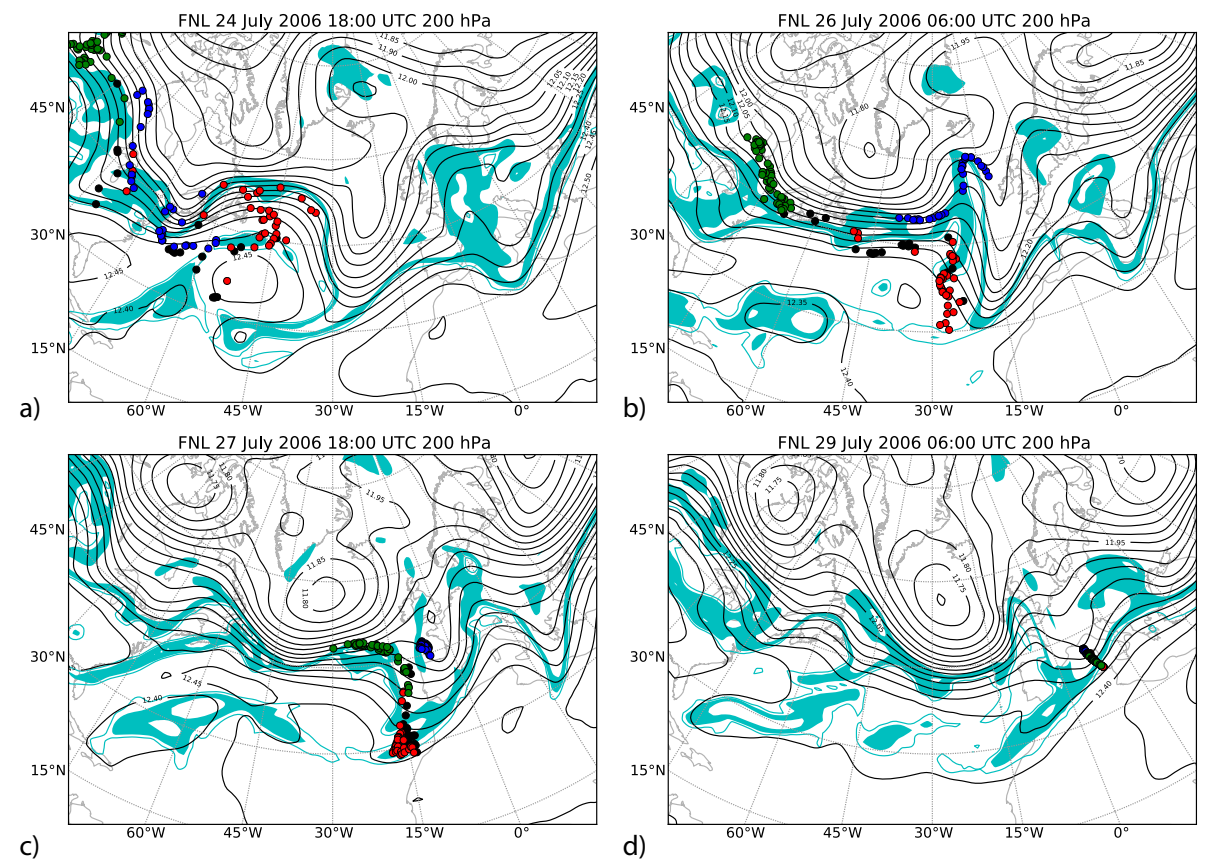

Fig. 8. Backward-trajectories of four groups of selected sets of air parcels. Black contour lines show geopotential height at $200 \mathrm{hPa}$. The cyan contour line indicates a potential vorticity of $1.5 \mathrm{PVU}$, while the cyan surface indicates a potential vorticity of 2 to $4 \mathrm{PVU}$ at $200 \mathrm{hPa}$. The coloured circles correspond to the horizontal position of the similarly coloured air parcels highlighted in Fig. 6 at the time given in the respective title.
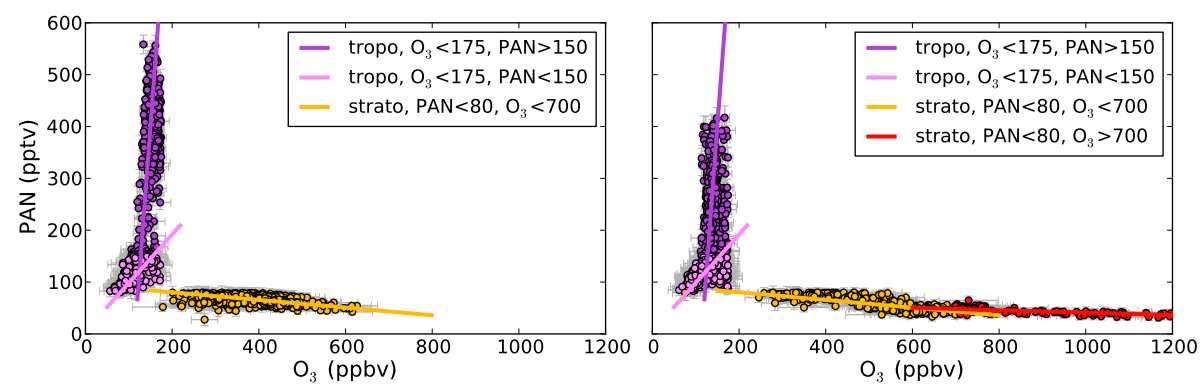

Fig. 9. The subsets of air parcels selected according to the four criteria and the slope derived for each set by the orthogonal distance regression (see Table 2). The western (left) and eastern (right) cross sections are shown separately. The precision of measurements is indicated by error bars in light grey.

variability between the stratospheric tracers and tropospheric tracers. In this case, a stratospheric branch is formed by the air mass with widely varying $\mathrm{O}_{3}$ VMRs and low PAN VMRs, and a tropospheric branch is formed by air mass with low $\mathrm{O}_{3}$ VMRs and high, widely varying PAN VMRs. We proceed to examine the $\mathrm{O}_{3}$-PAN relationship to identify mixing between stratospheric and tropospheric air.

The relationship between PAN and $\mathrm{O}_{3}$ for air parcels with an $\mathrm{O}_{3}$ VMR below $175 \mathrm{ppbv}$ (the chemically tropospheric branch) or a PAN VMR below 80 pptv (the chemically stratospheric branch) is depicted in Fig. 9 (subset of the data points) and Fig. 10 (all retrieved data points). The shape and clustering of the air parcels in tracer-tracer space suggest a further subdivision of air masses. In addition to the men- tioned criteria (of low $\mathrm{O}_{3}$ and PAN VMRs), the air masses are further separated into the four categories listed in Table 2 . The last column gives a descriptive name that fits the majority of the matching air parcels and which should be taken qualitatively (quotation marks highlight the use of these names in the following). The "clean tropospheric" air parcels stem from the Far East and are mostly located in the tropical troposphere above $12 \mathrm{~km}$. In contrast, the "polluted tropospheric" air parcels were mostly advected from the west and most can be found in the upper subtropical troposphere. The chemically stratospheric air parcels are similarly split. A distinction is made according to the $\mathrm{O}_{3}$ VMR, as a slope change is visible at $700 \mathrm{ppbv}$ in Fig. 9. The western cross section contains less air parcels with high $\mathrm{O}_{3}$ VMRs as the 

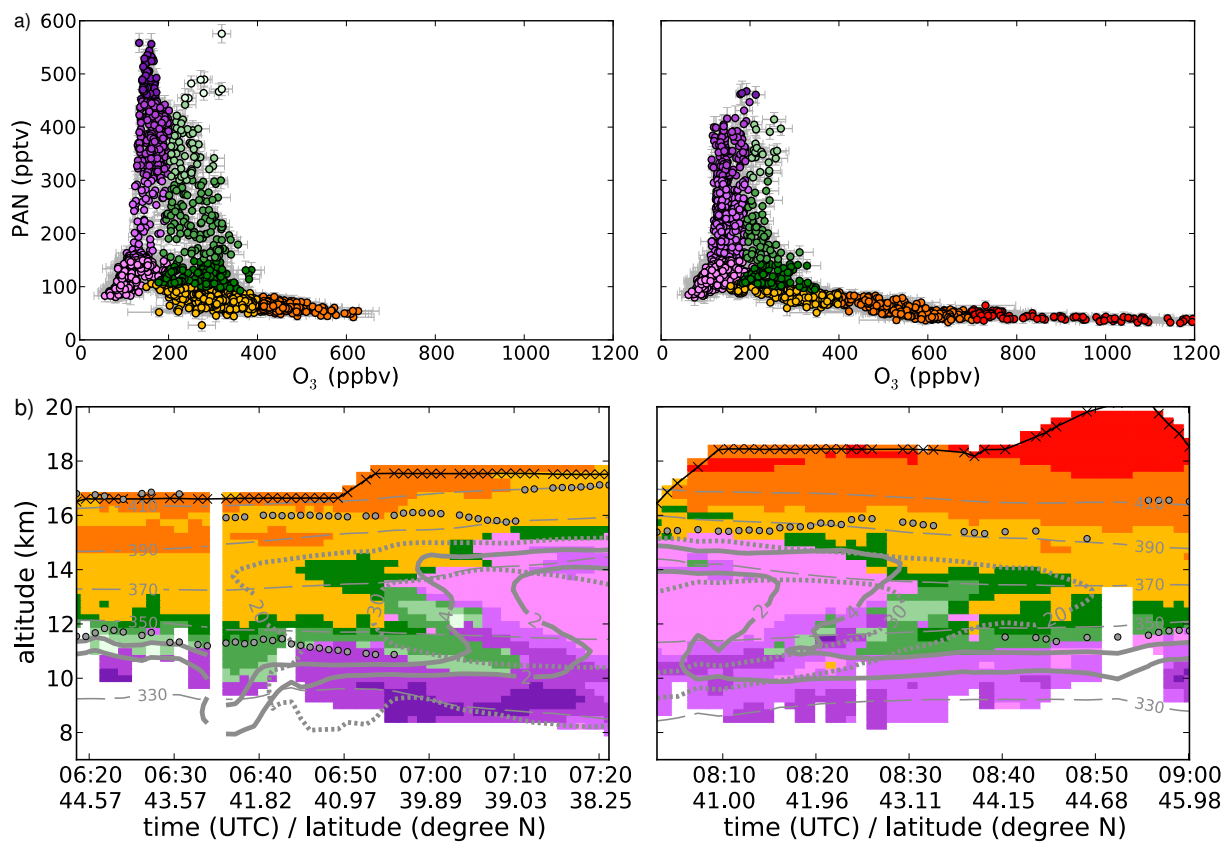

Fig. 10. Relationship between $\mathrm{PAN}$ and $\mathrm{O}_{3}$. Both panels show the western (left) and eastern (right) cross sections separately. (a) shows the location of air parcels in tracer-tracer space for all measured air parcels including error bars in light grey. Red colours indicate the stratospheric branch, purple colours indicate the tropospheric branch, and green colours indicate air parcels that could not be assigned to either category. Different shades of red are assigned according to $\mathrm{O}_{3}$ VMR (with thresholds of 400 and 700 ppbv). Different shades of green and purple are assigned according to PAN VMR (with thresholds of 150, 300, and 450 pptv). (b) shows the geo-spatial distribution of air parcels coloured according to their location in tracer-tracer space, i.e. with the same colours used in (a).
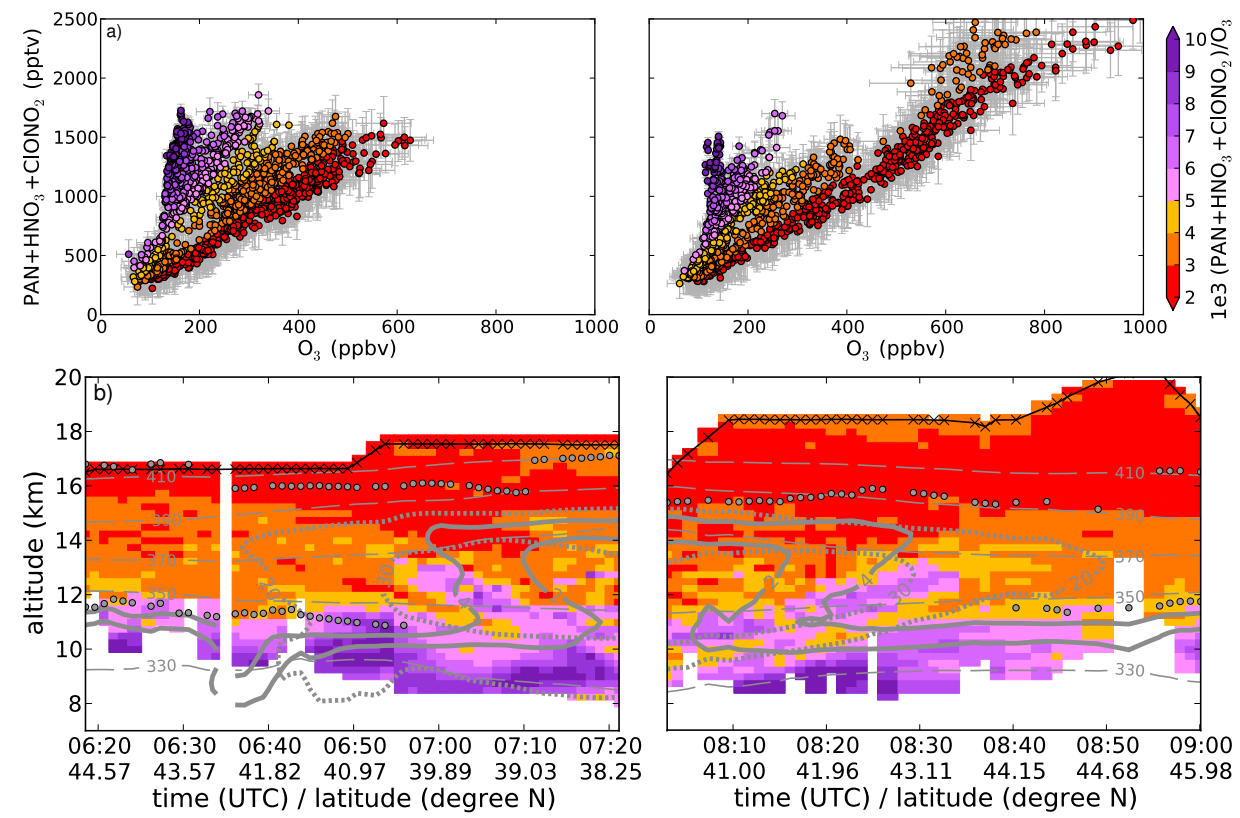

Fig. 11. Relationship of $\mathrm{PAN}+\mathrm{HNO}_{3}+\mathrm{ClONO}_{2}$ and $\mathrm{O}_{3}$. All panels show the western (left) and eastern (right) cross sections separately. (a) shows the location of air parcels in tracer-tracer space. The precision of measurements is indicated by error bars in light grey. Colours are assigned according to the ratio of volume mixing ratios. (b) shows the location of the same air parcels in geophysical space coloured with the same colours used in (a). 
Table 2. Correlation between $\mathrm{O}_{3}$ and PAN for different air masses. The selection criteria are listed in the first two columns. The third column gives the number of $n$ samples matching the selection criteria. An orthogonal distance regression fits the formula of PAN (pptv) $=$ $a \cdot \mathrm{O}_{3}$ (pptv) $+b$ (pptv). Columns four and five give $a$ and $b$ with the number in brackets being the standard deviation for the last two digits. A descriptive name fitting to the majority of matching air parcels is given in the last column to simplify the description.

\begin{tabular}{cccccl}
\hline $\mathrm{O}_{3}$ (ppbv) & PAN (pptv) & $n$ & $a$ & $b$ (pptv) & Descriptive name \\
\hline$<175$ & $\geq 150$ & 600 & $1.114(79) \times 10^{-2}$ & $-1.27(11) \times 10^{3}$ & polluted tropospheric \\
$<175$ & $<150$ & 447 & $9.33(65) \times 10^{-4}$ & $5.1(74) \times 10^{0}$ & clean tropospheric \\
$<700$ & $<80$ & 914 & $-7.38(23) \times 10^{-5}$ & $9.51(11) \times 10^{1}$ & middleworld \\
$\geq 700$ & $<80$ & 105 & $-2.34(28) \times 10^{-5}$ & $6.45(28) \times 10^{1}$ & overworld \\
\hline
\end{tabular}

Table 3. A list of employed integrated microwindows (IMW) and their spectral range.

\begin{tabular}{lclc}
\hline IMW & Range $\left(\mathrm{cm}^{-1}\right)$ & IMW & Range $\left(\mathrm{cm}^{-1}\right)$ \\
\hline 0 & $777.5-778.5$ & 7 & $808.0-809.0$ \\
1 & $784.0-785.0$ & 8 & $810.0-813.0$ \\
2 & $787.0-790.0$ & 9 & $820.5-821.5$ \\
3 & $791.5-793.0$ & 10 & $831.0-832.0$ \\
4 & $794.1-795.0$ & 11 & $846.0-847.0$ \\
5 & $795.5-796.5$ & 12 & $863.0-866.0$ \\
6 & $796.6-797.5$ & & \\
\hline
\end{tabular}

lower flight level of the aircraft during the first part of the research flight did not allow for measurements at high altitudes. In the given meteorological setting, the position of the resulting two groups roughly coincides with air parcels in the middleworld (below $\approx 420 \mathrm{~K}$ potential temperature; lower $\mathrm{O}_{3}$ VMRs) on the one hand and the overworld (above $\approx 420 \mathrm{~K}$ potential temperature; higher $\mathrm{O}_{3}$ VMRs) on the other hand. For each set of air parcels, an orthogonal distance regression (Boggs et al., 1987) was executed to derive PAN from $\mathrm{O}_{3}$ in a simple linear fashion taking the precision of both trace gas measurements into account. The resulting coefficients for all four sets are collected in Table 2. For each set of air parcels, the derived correlation is drawn as an appropriately coloured line in Fig. 9. The linear factor for "polluted tropospheric" air parcels is consistent with a similar regression of boundary layer air performed by Wunderli and Gehrig (1991); however, the constant offset is larger in this case, indicating a larger background VMR of $\mathrm{O}_{3}$ of 50 to $100 \mathrm{ppbv}$ that is consistent with typical $\mathrm{O}_{3}$ background values at this altitude.

Figure 10a shows the location of all retrieved air parcels in tracer-tracer space. There is an obvious gap in the eastern scatter-plot between the "clean tropospheric" air parcels and the "middleworld" air parcels. Also, more mixed air parcels with high $\mathrm{O}_{3}$ VMRs are found in the western cross section. Assuming that mixing processes follow straight lines, this distribution of mixed air parcels implies that tropospheric air parcels with PAN VMR $\geq 400$ pptv were in close spatial proximity with stratospheric air parcels with an $\mathrm{O}_{3}$ VMR of at least $400 \mathrm{ppbv}$. This is consistent with previous studies of STE that found frequent mixing between tropospheric and stratospheric air up to an $\mathrm{O}_{3}$ VMR of $400 \mathrm{ppbv}$ (e.g. Pan et al., 2004). In Fig. 5a, such air parcels can only be found upwards of $\approx 14 \mathrm{~km}$. This supports the hypothesis that the "high-stratospheric (red)" filament (referring to the red marked air parcels of Fig. 6) was generated by horizontal mixing between stratospheric and polluted tropospheric tropical air while circling the anti-cyclone at up to $\approx 14 \mathrm{~km}$. The upper half of this filament is thereby better mixed than the lower half, where the maxima of $\mathrm{HNO}_{3}$ and PAN are still separable.

Figure $10 \mathrm{~b}$ shows the geo-spatial position of categorised air parcels using the same colour scale that was used in Fig. 10a. Mixed air parcels (green shaded airmass) are classified as ExTL (e.g. Pan et al., 2004, 2007). This is the first time that measurements allow the ExTL structure to be displayed in a 2-D cross section. The three UTLS filaments of Sect. 3.3 can be readily identified, being categorised as consisting mostly of mixed air parcels.

The "high-stratospheric (red)" filament shows significant tropospheric influence up to $14 \mathrm{~km}$ altitude with especially high PAN VMRs around $12.5 \mathrm{~km}$. In contrast, the upper portion of the "middle-stratospheric (green)" filament (referring to the green marked air parcels of Fig. 6) shows no tropospheric influence in its northern half above $12 \mathrm{~km}$. However, the lower half, being in close spatial proximity to the subtropical troposphere, shows significant signs of mixing. Also the "low-stratospheric (blue)" filament (referring to the blue marked air parcels of Fig. 6) mostly consists of air categorised as mixed. Figure 10b shows the filament of decreased $\mathrm{HNO}_{3}$ VMRs between the "high-stratospheric (red)" and the "middle-stratospheric (green)" filament as consisting of mixed and stratospheric air. This filament consists likely of tropospheric air stemming from the clean upper tropical troposphere that contains only relatively low PAN VMRs. Thus, a rather small influx of stratospheric air with high $\mathrm{O}_{3}$ VMRs can easily change the chemical signature of the filament, as the position in tracer-tracer space of air parcels of "clean tropospheric" air parcels (light violet in Fig. 10a) and "middleworld" air parcels (light orange in Fig. 10a) are neighbouring each other. 
The vertical extent of the observed ExTL might be increased artificially due to the limited spatial resolution of the instrument. However, the vertical resolution at and above the thermal tropopause at $12 \mathrm{~km}$ is still $\approx 0.5 \mathrm{~km}$ for all three trace gases, which limits the potential overestimation of the vertical depth to approximately the same amount.

The extratropical UTLS shows a layered and complex structure, consisting of different filaments that are at various stages of mixing. UTLS air parcels just around and above the primary tropopause and thereby closest to the troposphere are most obviously influenced by mixing with the tropospheric air. In general, the ExTL is formed approximately $1 \mathrm{~km}$ around the primary tropopause. It extends to about $2 \mathrm{~km}$ near the poleward (cyclonic) flank of the jet core. This structure has been previously observed by in situ measurements that are limited to the flight track (Pan et al., 2007) and modelled (Konopka and Pan, 2012), but now it has been mapped out for the first time in a measured 2-D cross section. These new 2-D data reveal that the chemical air mass structure is very intricate and may often consist of multiple layers. The "high-stratospheric (red)" filament, consisting also of mixed air, extends up to $14 \mathrm{~km}$ altitude and more than $100 \mathrm{~km}$ northwards into the UTLS. This suggests that the thermal and dynamical tropopause exhibits breaks under the given meteorological circumstances.

\subsection{An NO y proxy for identifying pollution in the UTLS}

This section introduces a proxy for the total reactive nitrogen $\mathrm{NO}_{\mathrm{y}}$ from retrieved trace gases and uses this to estimate the influence of tropospheric pollution on air masses in the UTLS. The $\mathrm{NO}_{\mathrm{y}}$ proxy proves especially useful when combined with the available $\mathrm{O}_{3}$ measurements. $\mathrm{NO}_{\mathrm{y}}$ and $\mathrm{O}_{3}$ are well correlated in the lower stratosphere. This is not a consequence of a direct chemical connection, but because their source regions, sink regions, and lifetimes are similar, so that their distribution is jointly determined mostly by transport and mixing processes (Murphy et al., 1993). As the correlation is especially strong in the lowermost stratosphere, deviations thereof may be used to determine the origin of measured air masses.

The total reactive nitrogen plays an important role in the polluted and unpolluted atmosphere. It mainly consists of $\mathrm{NO}, \mathrm{NO}_{2}, \mathrm{PAN}, \mathrm{HNO}_{3}, \mathrm{HO}_{2} \mathrm{NO}_{2}$, and alkyl and multifunctional nitrates. According to Singh et al. (2007), PAN, $\mathrm{HNO}_{3}$, and $\mathrm{NO}_{\mathrm{x}}\left(=\mathrm{NO}+\mathrm{NO}_{2}\right)$ are the major contributors to $\mathrm{NO}_{\mathrm{y}}$ in the extratropical UTLS with a combined fractional percentage of about $95 \%$ on average. $\mathrm{NO}_{2}$ reacts with $\mathrm{OH}$ and a third-body to $\mathrm{HNO}_{3}$, which is in turn converted back to $\mathrm{NO}_{2}$ (and $\mathrm{OH}$ ) by photolysis. In the altitude range of the UTLS, the conversion to $\mathrm{HNO}_{3}$ is much faster than its destruction, so any stable equilibrium between $\mathrm{NO}_{2}$ and $\mathrm{HNO}_{3}$ will heavily favour $\mathrm{HNO}_{3}$ (Austin et al., 1986). As there are no $\mathrm{NO}_{\mathrm{x}}$ estimates available from CRISTA-NF measurements, only a proxy for $\mathrm{NO}_{\mathrm{y}}$ can be formed by the sum of the available dominant contributors $\mathrm{PAN}, \mathrm{HNO}_{3}$, and $\mathrm{ClONO}_{2}$. The latter trace gas could be neglected for the current atmospheric situation but would be important for the analysis of polar measurements. In the measurements of Singh et al. (2007), $\mathrm{NO}_{\mathrm{x}}$ was the major constituent of $\mathrm{NO}_{\mathrm{y}}$ close to the troposphere, so the given $\mathrm{NO}_{\mathrm{y}}$ proxy might underestimate the true $\mathrm{NO}_{\mathrm{y}}$ by a factor of 2 to 3 , depending on the altitude. But in contrast to the measurements of Singh et al. (2007), most of the air measured by CRISTA-NF should be free of recent influx caused by convection, so the $\mathrm{NO}_{\mathrm{x}}$ content should be much lower and the $\mathrm{HNO}_{3}$ content much higher due to prolonged ageing. Using the satellite instrument UARS, Morris et al. (1997) found a ratio of just 0.1 between $\mathrm{NO}_{\mathrm{x}}$ and $\mathrm{NO}_{\mathrm{y}}$ at $550 \mathrm{~K}(\approx 22 \mathrm{~km})$, implying that the proxy should become more reliable towards the flight level.

The ratio between $\mathrm{NO}_{y}$ and $\mathrm{O}_{3}$ is remarkably constant in the lower stratosphere and removes a lot of the inherent variability of the individual species. According to the measurements of Murphy et al. (1993), typical values for the ratio above $430 \mathrm{~K}$ potential temperature in the region observed by CRISTA-NF are 0.003 to 0.004 . Even though the available proxy likely underestimates $\mathrm{NO}_{\mathrm{y}}$, one can still deduce that a ratio larger than 0.004 indicates tropospheric influx of $\mathrm{NO}_{\mathrm{y}}$.

The relationship between the $\mathrm{NO}_{\mathrm{y}}$ proxy $\left(\mathrm{PAN}+\mathrm{HNO}_{3}+\mathrm{ClONO}_{2}\right)$ and $\mathrm{O}_{3}$ is depicted in Fig. 11a. The air parcels with the lowest VMRs of either the $\mathrm{NO}_{\mathrm{y}}$ proxy or $\mathrm{O}_{3}$ are again those of the upper tropical troposphere. Further, there is a set of predominantly stratospheric air parcels following the ratio of 0.002 to 0.004 . Air parcels with a ratio above 0.006 certainly consist of polluted air. The air parcels with ratios in between consist of less polluted or mixed air. The geo-spatial distribution of the air parcels is shown in Fig. 11b. The state of air parcels with a ratio below 0.004 cannot be determined reliably due to the missing $\mathrm{NO}_{\mathrm{x}}$. However, assuming that the measured air masses were not subject to a recent influx of freshly polluted air, air parcels with a ratio below 0.003 should consist of unpolluted stratospheric air (at the typical altitudes and location where these air parcels are found, $\mathrm{HNO}_{3}$ should be the major contributor so that the correct ratio of $\mathrm{NO}_{\mathrm{y}} / \mathrm{O}_{3}$ should still be less than 0.004 regardless of the $\mathrm{NO}_{\mathrm{x}}$ content).

In situ measurements for $\mathrm{NO}_{\mathrm{x}}, \mathrm{NO}_{\mathrm{y}}$, and $\mathrm{O}_{3}$ are usually available for such research flights. But this specific flight was a test flight, where not all instrumentation was mounted or turned on. For other campaigns, one might improve the proxy by identifying the correlations between $\mathrm{NO}_{\mathrm{x}}$ and available species and thereby derive an estimate for $\mathrm{NO}_{\mathrm{x}}$ by multiple linear regression. Still, if not all types of sounded air masses are also sampled by the in situ instruments, artefacts may arise due to the different history and ageing of air (Singh et al., 2007). In either case, this approach should reduce the error of the $\mathrm{NO}_{\mathrm{y}}$ estimate significantly.

Figure $11 \mathrm{~b}$ shows much less filamentary structure in the upper UTLS. This is a good indicator for the predominantly stratospheric origin of these air masses. Any 
significant tropospheric influence, as indicated by slightly elevated PAN and decreased $\mathrm{HNO}_{3}$ VMRs below the secondary tropopause in the western cross section, is therefore likely from the upper tropical troposphere. The increased ratios in the upper tropical troposphere between 12 and $14 \mathrm{~km}$ altitude are most likely an artefact caused by noise in the retrieved $\mathrm{O}_{3}$ VMRs, which affects the ratio more strongly for the very low $\mathrm{O}_{3}$ VMRs found in this region.

The previously discussed "high-stratospheric (red)" filament (see Fig. 6) is clearly marked by an increased ratio as high as 0.009 decreasing to $\approx 0.004$ in its uppermost part. Here, the influence and reach of polluted tropospheric air on UTLS is most visible. The corresponding filament in the western cross section shows this even better. Also the "lowstratospheric (blue)" air parcels of the stratospheric intrusion contain obviously elevated $\mathrm{NO}_{\mathrm{y}}$ levels.

The ratio between the $\mathrm{NO}_{y}$ proxy and $\mathrm{O}_{3}$ shows the pollution of involved air masses more clearly than the individual trace gases. Especially $\mathrm{HNO}_{3}$ exhibits a very filamentary structure in the UTLS, which is simplified by constructing the ratio. Thus, this technique enables a simple view on the pollution of air masses derivable fully from CRISTA-NF infrared remote sensing measurements.

\section{Discussion and conclusions}

This study presented a set of highly resolved trace gas cross sections derived from limb sounder measurements of CRISTA-NF. These trace gas cross sections, bridging the measurement gap between airborne in situ measurements and satellite-borne remote sensing instruments, represent the first multi-species 2-D chemical structure of the subtropical UTLS following an event of Rossby wave breaking. The presented data and analyses bring forth a number of new insights into chemical transport and chemical structure between the stratosphere and troposphere.

The observations showed a heavily layered structure with alternating filaments of predominantly stratospheric and tropospherically influenced air. The extent of the observed filaments is $\approx 0.8 \mathrm{~km}$ vertically and $\approx 200 \mathrm{~km}$ in across-jetstream direction. Fine-scale filamentary structure near the tropopause has been predicted by an idealised model (contour advection) as a consequence a dynamical stretching by the large-scale flow (Appenzeller et al., 1996). These filamentary structures, however, are often analysed on isentropic surfaces. The presented results show that these structures also exist in the vertical and that they may not always be aligned with the isentropes.

Backward trajectory analyses revealed that stirring by the jet dynamics resulted in the observed layered structure. Strong gradients in trace gas VMRs were observed along isentropes, especially in the vicinity of the tropopause fold. This may indicate that the processes leading up to the imaged situation involve non-adiabatic processes such as up- lift by a warm conveyor belt or gravity waves instigated by the baroclinic jet stream. Partly, this may be an artefact of an imperfect alignment between ECMWF temperature data and the position of retrieved trace gas parcels. As the trajectory calculations take into account only purely advective processes, it is important to complement this analysis with tracer-tracer relationships to identify mixing processes.

Having available multiple trace gas species offered the opportunity to characterise the chemical composition structure of the observed region in tracer-tracer space. The VMRs of $\mathrm{O}_{3}$ and PAN were used to identify predominantly tropospheric and stratospheric air masses. Connecting these results from tracer-tracer space with the geo-spatial space allowed for the first time deriving highly resolved cross sections with clear identification of a highly structured ExTL close to the subtropical jet stream. Due to a lack of high resolution measurements, the ExTL is often perceived as a homogeneous mixing layer around the tropopause (e.g. Gettelman et al., 2011). The presented results show that the real atmosphere is likely much more complicated, and that the ExTL is likely highly structured and inhomogeneous.

In addition, the influence of polluted tropospheric air masses on the stratosphere was examined using the sum of $\mathrm{HNO}_{3}, \mathrm{ClONO}_{2}$, and PAN divided by $\mathrm{O}_{3}$. This ratio is rather stable in the lower stratosphere and deviations indicate abnormal chemical processes (such as occur in the polar winter) or mixing with (polluted) tropospheric air masses. This ratio complemented the picture given by the $\mathrm{O}_{3}$-PAN relationship and showed the influence of pollution to be largely restricted to the ExTL.

In combination, this demonstrates a rich spatial structure of the UTLS region at the subtropical jet, where the tropopause break is perturbed by breaking Rossby waves. The induced stirring brings into close contact air masses from stratospheric and tropospheric origin resulting in a complex structure of entangled filaments. How long does it take the observed filaments to lose their characteristics due to diffusion, small-scale turbulence, and further stirring? In the given meteorological setting (end of July over the Northern Atlantic), wave breaking could be observed on nearly a daily basis. These filamentary structures are likely a ubiquitous feature of the subtropical UTLS. We may ask, what is the effect of this layered structure on chemical and radiative processes? How should they be represented in global chemistryclimate models? Most global chemistry-climate models represent the UTLS with a vertical resolution of $\approx 1 \mathrm{~km}$ or worse (e.g. Hegglin et al., 2010), which is not sufficient to reproduce the observed fine-scale structure. These questions demand more high-resolution measurements of this kind, beyond the spatial and temporal coverage provided by this single flight.

Still, the presented data set serves as a good example of the capabilities of infrared limb sounders. The vertical resolution of the discussed trace gases is mostly in the range of $0.5 \mathrm{~km}$, but can go as low as $0.3 \mathrm{~km}$ for $\mathrm{HNO}_{3}$. This 
excellent resolution proved sufficient but also needed to map the very fine details and structures in the UTLS. An instrument with a smaller field-of-view and finer sampling might even achieve a better vertical resolution and reproduce more details.

The evaluation of measurements was hindered in this case by the limited spectral range and spectral resolution available for the given flight. A modern airborne limb imager would have been able to retrieve more species at even higher vertical and horizontal resolution (Ungermann et al., 2011). Using near-future satellite infrared limb imagers, several parallel cross sections of only slightly reduced quality will be attainable from space (ESA, 2012). Such a satellite-borne instrument would have the obvious advantage of providing three-dimensional global coverage for several years to come, allowing for the deduction of, e.g. a filament climatology and the direct observation of the development of such filaments in time, which would allow quantitative insight in the stirring and mixing processes. Thus, infrared limb imagers prove as a valuable tool for the study of the highly complex UTLS region.

\section{Appendix A}

\section{Retrieval}

This appendix shortly recaptures the retrieval of trace gas VMRs from spectrally resolved infrared radiances measured by the CRISTA-NF instrument. A detailed description of the first retrieval of this set of measurements is given by Weigel et al. (2012). Ungermann et al. (2012) improved this setup by employing a more accurate line-of-sight determination and a finer retrieval grid. In addition, horizontal regularisation was added to lower the impact of stochastic error sources on the results (see Ungermann, 2013).

Retrieving trace gas VMRs from limb sounder measurements is an ill-posed problem. This implies that many or no trace gas profiles might fit to the imperfect measurements and that small measurement errors may have a large effect on retrieved VMRs. One counter-acts this by approximating the original ill-posed problem by a (well-posed) problem that is less affected by these problems. This approximation is often called regularisation (e.g. Tikhonov and Arsenin, 1977; Rodgers, 2000). Here, the approximation of minimising a quadratic form, i.e. the cost function $J: \mathbb{R}^{n} \mapsto \mathbb{R}$ is used to identify a unique solution:

$$
J(x)=(F(x)-y)^{\mathrm{T}} \mathbf{S}_{\epsilon}^{-1}(F(\boldsymbol{x})-\boldsymbol{y})+\left(\boldsymbol{x}-\boldsymbol{x}_{\mathrm{a}}\right)^{\mathrm{T}} \mathbf{S}_{\mathrm{a}}^{-1}\left(\boldsymbol{x}-\boldsymbol{x}_{\mathrm{a}}\right) .
$$

The vector $\boldsymbol{x}$ represents the atmospheric state of a cross section (assuming homogeneity in the line-of-sight direction) and some instrument parameters. The vector $\boldsymbol{y}$ consists of the measured radiances. The function $F: \mathbb{R}^{n} \mapsto \mathbb{R}^{m}$ is a (forward) model that produces synthetic measurements given an atmospheric state. The matrix $\mathbf{S}_{\epsilon}$ is a covariance matrix de-
Table A1. Correlation lengths employed for the regularisation.

\begin{tabular}{llll}
\hline Parameter & Value & Parameter & Value \\
\hline$c_{\text {temperature }}$ & $0.6 \mathrm{~km}$ & $c_{\mathrm{H}_{2} \mathrm{O}}$ & $300 \mathrm{~km}$ \\
$c_{\text {aerosol }}$ & $640 \mathrm{~km}$ & $c_{\mathrm{HCFC}-22}$ & $9.6 \mathrm{~km}$ \\
$c_{\mathrm{CCl}}$ & $0.3 \mathrm{~km}$ & $c_{\mathrm{HNO}_{3}}$ & $0.5 \mathrm{~km}$ \\
$c_{\mathrm{CFC}-11}$ & $0.3 \mathrm{~km}$ & $c_{\mathrm{O}_{3}}$ & $4.8 \mathrm{~km}$ \\
$c_{\mathrm{ClONO}_{2}}$ & $120 \mathrm{~km}$ & ${ }_{\text {PAN }}$ & $0.3 \mathrm{~km}$ \\
\hline
\end{tabular}

scribing the available knowledge about measurement errors. The vector $\boldsymbol{x}_{\mathrm{a}}$ and associated covariance matrix $\mathbf{S}_{\mathrm{a}}$ describe the available a priori knowledge about the atmospheric state.

A set of 12 integrated microwindows is employed in this multi-target retrieval. A comprehensive list is given in Table 3. The quantities of temperature, aerosol (extinction), $\mathrm{CCl}_{4}, \mathrm{CFC}-11, \mathrm{ClONO}_{2}, \mathrm{HCFC}-22, \mathrm{H}_{2} \mathrm{O}, \mathrm{HNO}_{3}, \mathrm{O}_{3}$, and PAN are retrieved. The primary targets are $\mathrm{HNO}_{3}, \mathrm{O}_{3}$, and PAN, while the remainder is mostly retrieved to reduce systematic errors in the primary targets. ECMWF analysis data is used as a priori for temperature, pressure, and water vapour. For PAN, a zero profile is employed. The other targets are initialised using the climatology of Remedios et al. (2007).

The gases $\mathrm{C}_{2} \mathrm{H}_{6}, \mathrm{HCFC}-22, \mathrm{HNO}_{4}, \mathrm{CFC}-12$, and CFC114 contribute a small percentage to the measured radiation and thus have to be included in the forward model. Further, the VMRs of $\mathrm{CO}_{2}$ have to be adjusted for the annual increase and inter-annual variability. The discussed results are not sensitive to the assumed VMRs for these gases. However, the simulated radiances agree better with the measured radiances when these gases are initialised according to a model run of the Whole Atmosphere Community Climate Model, version 4 (WACCM4; Garcia et al., 2007). The specific parametrisation for the used model run can be found in the publications of Lamarque et al. (2012) and Kunz et al. (2011b). While it is plausible that the use of WACCM model data reduces the systematic error caused by these background gases, their assumed standard deviations were not correspondingly reduced for the estimation of retrieval accuracy.

The a priori covariance matrix is assembled by Tikhonov regularisation modelled after the auto-regressive model of optimal estimation (see Ungermann et al., 2012). In effect, a constraint on the deviation of absolute value from the a priori vector $\boldsymbol{x}_{\mathrm{a}}$ is combined with two constraints on the deviation between the derivatives of the state vector $\boldsymbol{x}$ in vertical and isentropic direction and the corresponding derivatives of the a priori vector. These constraints are weighted with the standard deviations supplied by Remedios et al. (2007) (with the exceptions of temperature, for which $1 \mathrm{~K}$ was used, and PAN that uses values supplied by Glatthor et al., 2007) and with weights specific for each target as collected in Table A1. The constraint for the isentropic derivative is multiplied with an empirical factor of 333 to compensate for the different 
vertical and horizontal scales of synoptic structures. These parameters were chosen as result of a parameter study with the intent of using the weakest possible constraints for the primary targets while keeping visible noise to a minimum. Care was taken so that no isentropic structures were introduced by the application of isentropic regularisation that are not also discernible in the underlying radiances and conventional 1-D retrievals.

The weight of the a priori absolute value constraint is reduced by a factor of 10 compared to the constraints on the derivative. This reduces the bias of the absolute values of the solution towards the a priori vector and increases the measurement contribution.

The true measurement error covariance matrix is approximated by an uncorrelated error budget of $1 \%$. The major components of the measurement error are uncertainty in elevation angle of the measurement and noise of the detector. The chosen budget very likely overestimates the combined error and might thereby be partly responsible for the small correlation lengths in Table A1. This would imply that the supplied precision figures overestimate the true precision.

The model and retrieval software employed for the simulation of radiances is the Jülich Rapid Spectral Simulation Code Version 2. This Python/C++-based model and its predecessor were used in several experiments and studies (e.g. Hoffmann et al., 2008; Eckermann et al., 2009; Ungermann et al., 2010). The joint retrieval of the western cross section poses a problem with 32224 unknowns and 26584 measured radiances (the eastern one is similar). All involved matrices are stored using sparse representations. The minimisation of the cost-function is performed using a truncated quasiNewton method employing conjugate gradients for the solution to the posed linear equation systems. It requires five iterations for the given setup and thereby five evaluations of the Jacobian matrix that are calculated by an analytic adjoint model (Lotz et al., 2012). Using eight cores, this is accomplished in $18 \mathrm{~min}$. Providing the diagnostic parameters of precision, accuracy, and measurement contribution takes another $17 \mathrm{~min}$ on the same eight cores.

Acknowledgements. D. E. Kinnision, NCAR, is thanked for kindly providing the WACCM4 model data used in the retrieval. K. Bowman is thanked for making his trajectory model TRAJ3D available for this study. We sincerely thank A. Dudhia, Uni. Oxf., for providing the Reference Forward Model (RFM) used to calculate the optical path tables required by our forward model. The team of the Michelson Interferometer for Passive Atmospheric Sounding Aircraft (MIPAS-STR) is thanked for providing their attitude measurements that significantly improved our retrievals. We especially thank M. Shapiro, B. Ridley, F. Flocke, and many other National Center for Atmospheric Research (NCAR) scientists for fruitful discussions.

The AMMA-SCOUT-O3 measurement campaign was facilitated by the European Commission and the EC Integrated Project SCOUT-O3 (505390-GOCE-CT-2004) and AMMA. Based on a
French initiative, AMMA was set up by an international scientific group and is currently funded by a large number of agencies. It has been the beneficiary of a major financial contribution from the European Communities Sixth Framework Research Program.

J. Ungermann was supported by the Deutsche Forschungsgemeinschaft (GZ UN 311/1-1 and GZ KA2324/1-2) and the visitor's program of the Atmospheric Chemistry Division at the NCAR. NCAR is funded by the National Science Foundation (NSF). The European Centre for Medium-Range Weather Forecasts (ECMWF) and the National Centers for Environmental Prediction (NCEP) are acknowledged for meteorological data support. The NCEP-GFS data for this study are from the Research Data Archive (RDA) which is maintained by the Computational and Information Systems Laboratory (CISL) at NCAR. The original data are available from the RDA (http://rda.ucar.edu) in data set number ds083.2.

The service charges for this open access publication

have been covered by a Research Centre of the

Helmholtz Association.

Edited by: T. J. Dunkerton

\section{References}

Appenzeller, C., Davies, H. C., and Norton, W. A.: Fragmentation of stratospheric intrusions, J. Geophys. Res., 101, 1435-1456, doi:10.1029/95JD02674, 1996.

Austin, J., Garcia, R. R., Russell III, J. M., Solomon, S., and Tuck, A. F.: On the Atmospheric Chemistry of Nitric Acid, J. Geophys. Res., 91, 5477-5485, doi:10.1029/JD091iD05p05477, 1986.

Bernath, P. F., McElroy, C. T., Abrams, M. C., Boone, C. D., Butler, M., Camy-Peyret, C., Carleer, M., Clerbaux, C., Coheur, P.F., Colin, R., DeCola, P., DeMazière, M., Drummond, J. R., Dufour, D., Evans, W. F. J., Fast, H., Fussen, D., Gilbert, K., Jennings, D. E., Llewellyn, E. J., Lowe, R. P., Mahieu, E., McConnell, J. C., McHugh, M., McLeod, S. D., Michaud, R., Midwinter, C., Nassar, R., Nichitiu, F., Nowlan, C., Rinsland, C. P., Rochon, Y. J., Rowlands, N., Semeniuk, K., Simon, P., Skelton, R., Sloan, J. J., Soucy, M.-A., Strong, K., Tremblay, P., Turnbull, D., Walker, K. A., Walkty, I., Wardle, D. A., Wehrle, V., Zander, R., and Zou, J.: Atmospheric Chemistry Experiment (ACE): mission overview, Geophys. Res. Lett., 32, L15S01, doi:10.1029/2005GL022386, 2005.

Berthet, G., Esler, J. G., and Haynes, P. H.: A Lagrangian perspective of the tropopause and the ventilation of the lowermost stratosphere, J. Geophys. Res., 112, D18102, doi:10.1029/2006JD008295, 2007.

Boggs, P. T., Byrd, R. H., and Schnabel, R. B.: A stable and efficient algorithm for nonlinear orthogonal distance regression, SIAM J. Sci. Stat. Comput., 8, 1052-1078, doi:10.1137/0908085, 1987.

Bowman, K. P.: Large-scale isentropic mixing properties of the Antarctic polar vortex from analyzed winds, J. Geophys. Res., 98, 23013-23027, doi:10.1029/93JD02599, 1993.

Bowman, K. P. and Carrie, G. D.: The mean-meridional transport circulation of the troposphere in an idealized GCM, J. Atmos. Sci., 59, 1502-1514, doi:10.1175/15200469(2002)059<1502:TMMTCO>2.0.CO;2, 2002.

Cairo, F., Pommereau, J. P., Law, K. S., Schlager, H., Garnier, A., Fierli, F., Ern, M., Streibel, M., Arabas, S., Borrmann, S., Berthe- 
lier, J. J., Blom, C., Christensen, T., D’Amato, F., Di Donfrancesco, G., Deshler, T., Diedhiou, A., Durry, G., Engelsen, O., Goutail, F., Harris, N. R. P., Kerstel, E. R. T., Khaykin, S., Konopka, P., Kylling, A., Larsen, N., Lebel, T., Liu, X., MacKenzie, A. R., Nielsen, J., Oulanowski, A., Parker, D. J., Pelon, J., Polcher, J., Pyle, J. A., Ravegnani, F., Rivière, E. D., Robinson, A. D., Röckmann, T., Schiller, C., Simões, F., Stefanutti, L., Stroh, F., Some, L., Siegmund, P., Sitnikov, N., Vernier, J. P., Volk, C. M., Voigt, C., von Hobe, M., Viciani, S., and Yushkov, V.: An introduction to the SCOUT-AMMA stratospheric aircraft, balloons and sondes campaign in West Africa, August 2006: rationale and roadmap, Atmos. Chem. Phys., 10, 2237-2256, doi:10.5194/acp-10-2237-2010, 2010.

Chen, P.: Isentropic cross-tropopause mass exchange in the extratropics, J. Geophys. Res., 100, 16661-16673, doi:10.1029/95JD01264, 1995.

Danielsen, E. F.: Stratospheric-tropospheric exchange based on radioactivity, ozone, and potential vorticity, J. Atmos. Sci., 25, 502-518, doi:10.1175/15200469(1968)025<0502:STEBOR>2.0.CO;2, 1968.

Dunkerton, T.: Evidence of meridional motion in the summer lower stratosphere adjacent to monsoon regions, J. Geophys. Res., 100, 16675-16688, doi:10.1029/95JD01263, 1995.

Eckermann, S. D., Hoffmann, L., Höpfner, M., Wu, D. L., and Alexander, M. J.: Antarctic NAT PSC belt of June 2003: observational validation of the mountain wave seeding hypothesis, Geophys. Res. Lett., 36, L02807, doi:10.1029/2008GL036629, 2009.

ESA: Report for Mission Selection: PREMIER, vol. SP-1324/3, ESA Communication Production Office, Noordwijk, The Netherlands, 2012.

Fischer, H., Birk, M., Blom, C., Carli, B., Carlotti, M., von Clarmann, T., Delbouille, L., Dudhia, A., Ehhalt, D., Endemann, M., Flaud, J. M., Gessner, R., Kleinert, A., Koopman, R., Langen, J., López-Puertas, M., Mosner, P., Nett, H., Oelhaf, H., Perron, G., Remedios, J., Ridolfi, M., Stiller, G., and Zander, R.: MIPAS: an instrument for atmospheric and climate research, Atmos. Chem. Phys., 8, 2151-2188, doi:10.5194/acp-8-2151-2008, 2008.

Friedl-Vallon, F., Riese, M., Maucher, G., Lengel, A., Hase, F., Preusse, P., and Spang, R.: Instrument concept and preliminary performance analysis of GLORIA, Adv. Space Res., 37, 22872291, doi:10.1016/j.asr.2005.07.075, 2006.

Garcia, R. R., Marsh, D., Kinnison, D. E., Boville, B., and Sassi, F.: Simulations of secular trends in the middle atmosphere 1950-2003, J. Geophys. Res., 112, D09301, doi:10.1029/2006JD007485, 2007.

Gettelman, A., Hoor, P., Pan, L. L., Randel, W. J., Hegglin, M. I., and Birner, T.: The extra tropical upper troposphere and lower stratosphere, Rev. Geophys., 49, RG3003, doi:10.1029/2011RG000355, 2011.

Gille, J. C., Barnett, J., Arter, P., Barker, M., Bernath, P., Boone, C., Cavanaugh, C., Chow, J., Coffey, M., Craft, J., Craig, C., Dials, M., Dean, V., Eden, T., Edwards, D. P., Francis, G., Halvorson, C., Harvey, L., Hepplewhite, C., Khosravi, R., Kinnison, D., Krinsky, C., Lambert, A., Lee, H., Lyjak, L., Loh, J., Mankin, W., Massie, S., McInerney, J., Moorhouse, J., Nardi, B., Packman, D., Randall, C., Reburn, J., Rudolf, W., Schwartz, M., Serafin, J., Stone, K., Torpy, B., Walker, K., Waterfall, A., Watkins, R., Whitney, J., Woodard, D., and Young, G.: The HighResolution Dynamics Limb Sounder: Experiment overview, re- covery, and validation of initial temperature data, J. Geophys. Res., 113, D16S43, doi:10.1029/2007JD008824, 2008.

Glatthor, N., von Clarmann, T., Fischer, H., Funke, B., Grabowski, U., Höpfner, M., Kellmann, S., Kiefer, M., Linden, A., Milz, M., Steck, T., and Stiller, G. P.: Global peroxyacetyl nitrate (PAN) retrieval in the upper troposphere from limb emission spectra of the Michelson Interferometer for Passive Atmospheric Sounding (MIPAS), Atmos. Chem. Phys., 7, 27752787, doi:10.5194/acp-7-2775-2007, 2007.

Grossmann, K. U., Offermann, D., Gusev, O., Oberheide, J., Riese, M., and Spang, R.: The CRISTA-2 mission, J. Geophys. Res., 107, 8173, doi:10.1029/2001JD000667, 2002.

Haynes, P., Scinocca, J., and Greenslade, M.: Formation and maintenance of the extratropical tropopause by baroclinic eddies, Geophys. Res. Lett., 28, 4179-4182, doi:10.1029/2001GL013485, 2001.

Hegglin, M. I., Boone, C. D., Manney, G. L., and Walker, K. A.: A global view of the extratropical tropopause transition layer from Atmospheric Chemistry Experiment Fourier Transform Spectrometer $\mathrm{O}_{3}, \mathrm{H}_{2} \mathrm{O}$, and CO, J. Geophys. Res., 114, D00B11, doi:10.1029/2008JD009984, 2009.

Hegglin, M. I., Gettelman, A., Hoor, P., Krichevsky, R., Manney, G., Pan, L. L., Son, S.-W., Stiller, G., Tilmes, S., Walker, K. A., Eyring, V., Shepherd, T. G., Waugh, D., Akiyoshi, H., Anel, J. A., Austin, J., Baumgaertner, A., Bekki, S., Braesicke, P., Brühl, C., Butchart, N., Chipperfield, M., Dhomse, S., Frith, S., Garny, H., Hardiman, S., Jöckel, P., Kinnison, D., Lamarque, J., Mancini, E., Michou, M., Morgenstern, O., Nakamura, T., Olivié, D., Pawson, S., Pitari, G., Plummer, D., Pyle, J., Rozanov, E., Scinocca, J., Shibata, K., Smate, D., Teyssèdre, H., Tian, W., and Yamashita, Y.: Multimodel assessment of the upper troposphere and lower stratosphere: extratropics, J. Geophys. Res., 115, D00M09, doi:10.1029/2010JD013884, 2010.

Hintsa, E. J., Boering, K. A., Weinstock, E. M., Anderson, J. G., Gary, B. L., Pfister, L., Daube, B. C., Wofsy, S. C., Loewenstein, M., Podolske, J. R., Margitan, J. J., and Bui, T. P.: Troposphere-to-stratosphere transport in the lowermost stratosphere from measurements of $\mathrm{H}_{2} \mathrm{O}, \mathrm{CO}_{2}, \mathrm{~N}_{2} \mathrm{O}$ and $\mathrm{O}_{3}$, Geophys. Res. Lett., 25, 2655-2658, doi:10.1029/98GL01797, 1998.

Hoerling, M. P., Schaack, T. K., and Lenzen, A. J.: Global objective tropopause analysis, Mon. Weather Rev., 119, 1816-1831, 1991.

Hoffmann, L., Kaufmann, M., Spang, R., Müller, R., Remedios, J. J., Moore, D. P., Volk, C. M., von Clarmann, T., and Riese, M.: Envisat MIPAS measurements of CFC-11: retrieval, validation, and climatology, Atmos. Chem. Phys., 8, 3671-3688, doi:10.5194/acp-8-3671-2008, 2008.

Holton, J. R., Haynes, P. H., McIntyre, M. E., Douglass, A. R., Rood, R. B., and Pfister, L.: Stratosphere-troposphere exchange, Rev. Geophys., 33, 403-439, 1995.

Homeyer, C. R., Bowman, K. P., Pan, L. L., Atlas, E. L., Gao, R.S., and Campos, T. L.: Dynamical and chemical characteristics of tropospheric intrusions observed during START08, J. Geophys. Res., 116, D06111, doi:10.1029/2010JD01509, 2011.

Hoor, P., Fischer, H., Lange, L., Lelieveld, J., and Brunner, D.: Seasonal variations of a mixing layer in the lowermost stratosphere as identified by the $\mathrm{CO}-\mathrm{O}_{3}$ correlation from in situ measurements, J. Geophys. Res., 107, 4004, doi:10.1029/2000JD000289, 2002. 
Konopka, P. and Pan, L. L.: On the mixing-driven formation of the Extratropical Transition Layer (ExTL), J. Geophys. Res., 117, D18301, doi:10.1029/2012JD017876, 2012.

Kullmann, A., Riese, M., Olschewski, F., Stroh, F., and Grossmann, K. U.: Cryogenic Infrared Spectrometers and Telescopes for the Atmosphere - New Frontiers, in: Proc. SPIE, vol. 5570, 423-432, doi:10.1117/12.564856, 2004.

Kunz, A., Konopka, P., Müller, R., and Pan, L. L.: Dynamical tropopause based on isentropic potential vorticity gradients, J. Geophys. Res., 116, D01110, doi:10.1029/2010JD014343, 2011a.

Kunz, A., Pan, L. L., Konopka, P., Kinnison, D., and Tilmes, S.: Chemical and dynamical discontinuity at the extratropoical tropopause based on START08 and WACCM analysis, J. Geophys. Res., 116, D24302, doi:10.1029/2011JD016686, $2011 \mathrm{~b}$.

Lamarque, J.-F., Emmons, L. K., Hess, P. G., Kinnison, D. E., Tilmes, S., Vitt, F., Heald, C. L., Holland, E. A., Lauritzen, P. H., Neu, J., Orlando, J. J., Rasch, P. J., and Tyndall, G. K.: CAMchem: description and evaluation of interactive atmospheric chemistry in the Community Earth System Model, Geosci. Model Dev., 5, 369-411, doi:10.5194/gmd-5-369-2012, 2012.

Lin, Y. and Zhang, F.: Tracking gravity waves in baroclinic jet-front systems, J. Atmos. Sci., 65, 2402-2415, doi:10.1175/2007JAS2482.1, 2008.

Lotz, J., Naumann, U., and Ungermann, J.: Hierarchical algorithmic differentiation - a case study, in: Recent Advances in Algorithmic Differentiation, edited by Forth, S., Hovland, P., Phipps, E., Utke, J., and Walther, A., Lecture Notes in Computational Science and Engineering, vol. 87, Springer, New York, USA, doi:10.1007/978-3-642-30023-3_17, 187-196, 2012.

McIntyre, M. E. and Palmer, T. N.: The "surf zone" in the stratosphere, J. Atm. Terr. Phys., 46, 825-849, 1984.

Morris, G. A., Considine, D. B., Dessler, A. E., Kawa, S. R., Kumer, J., Mergenthaler, J., Roche, A., and Russell III, J. M.: Nitrogen partitioning in the middle stratosphere as observed by the upper atmosphere research satellite, J. Geophys. Res., 102, 8955-8965, doi:10.1029/97JD00073, 1997.

Murphy, D. M., Fahey, D. W., Proffitt, M. H., Liu, S. C., Chan, K. R., Eubank, C. S., Kawa, S. R., and Kelly, K. K.: Reactive nitrogen and its correlation with ozone in the lower stratosphere and upper troposphere, J. Geophys. Res., 98, 8751-8773, doi:10.1029/92JD00681, 1993.

Offermann, D., Grossmann, K.-U., Barthol, P., Knieling, P., Riese, M., and Trant, R.: Cryogenic Infrared Spectrometers and Telescopes for the Atmosphere (CRISTA) experiment and middle atmosphere variability, J. Geophys. Res., 104, 16311-16325, doi:10.1029/1998JD100047, 1999.

Pan, L. L., Randel, W. J., Gary, B. L., Mahoney, M. J., and Hintsa, E. J.: Definitions and sharpness of the extratropical tropopause: a trace gas perspective, J. Geophys. Res., 109, D23103, doi:10.1029/2004JD004982, 2004.

Pan, L. L., Bowman, K. P., Shaphiro, M., Randel, W. J., Gao, R.-S., Campos, T., Favis, C., Schauffler, S., Ridley, B. A., Wei, J. C., and Barnet, C.: Chemical behavior of the tropopause observed during the Stratosphere-Troposphere Analyses of Regional Transport (START) experiment, J. Geophys. Res., 112, D18110, doi:10.1029/2007JD008645, 2007.

Pan, L. L., Randel, W. J., Gille, J. C., Hall, W. D., Nardi, B., Massie, S., Yudin, V., Khosravi, R., Konopka, P., and Tarasick, D.: Tropospheric intrusions associated with the secondary tropopause, J. Geophys. Res., 114, D10302, doi:10.1029/2008JD011374, 2009.

Penketi, S. A., Sandalls, F. J., and Lovelock, J. F.: Observations of peroxyacetyl nitrate (PAN) in air in Southern England, Atmos. Environment, 9, 139-140, doi:10.1016/0004-6981(75)90063-3, 1975.

Postel, G. A. and Hitchman, M. H.: A climatology of Rossby wave breaking along the subtropical tropopause, J. Atmos. Sci., 56, 359-373, doi:10.1175/15200469(1999)056<0359:ACORWB>2.0.CO;2, 1999.

Remedios, J. J., Leigh, R. J., Waterfall, A. M., Moore, D. P., Sembhi, H., Parkes, I., Greenhough, J., Chipperfield, M.P., and Hauglustaine, D.: MIPAS reference atmospheres and comparisons to V4.61/V4.62 MIPAS level 2 geophysical data sets, Atmos. Chem. Phys. Discuss., 7, 9973-10017, doi:10.5194/acpd-79973-2007, 2007.

Riese, M., Friedl-Vallon, F., Spang, R., Preusse, P., Schiller, C., Hoffmann, L., Konopka, P., Oelhaf, H., von Clarmann, T., and Höpfner, M.: GLObal limb Radiance Imager for the Atmosphere (GLORIA): scientific objectives, Adv. Space Res., 36, 989-995, doi:10.1016/j.asr.2005.04.115, 2005.

Riese, M., Ploeger, F., Rap, A., Vogel, B., Konopka, P., Dameris, M., and Forster, P.: Impact of uncertainties in atmospheric mixing on simulated UTLS composition and related radiative effects, J. Geophys. Res., 117, D16305, doi:10.1029/2012JD017751, 2012.

Roberts, J. M.: The atmospheric chemistry of organic nitrates, Atmos. Environ., 24, 243-287, doi:10.1016/0960-1686(90)90108Y, 1990.

Rodgers, C. D.: Inverse Methods for Atmospheric Sounding: Theory and Practice, Series on Atmospheric, Oceanic and Planetary Physics, vol. 2, World Scientific, Singapore, 2000.

Schroeder, S., Kullman, A., Preusse, P., Stroh, F., Weigel, K., Ern, M., Knieling, P., Olschewski, F., Spang, R., and Riese, M.: Radiance calibration of CRISTA-NF, Adv. Space Res., 43, 19101917, doi:10.1016/j.asr.2009.03.009, 2009.

Singh, H. B., Salas, L. J., and Viezee, W.: Global distribution of peroxyacetyl nitrate, Nature, 321, 588-591, doi:10.1038/321588a0, 1986.

Singh, H. B., Salas, L., Herlth, D., Kolyer, R., Czech, E., Avery, M., Crawford, J. H., Pierce, R. B., Sachse, G. W., Blake, D. R., Cohen, R. C., Bertram, T. H., Perring, A., Wooldridge, P. J., Dibb, J., Huey, G., Hudman, R. C., Turquety, S., Emmons, L. K., Flocke, F., Tang, Y., Carmichael, G. R., and Horowitz, L. W.: Reactive nitrogen distribution and partitioning in the North American troposphere and lowermost stratosphere, J. Geophys. Res., 112, D12S04, doi:10.1029/2006JD007664, 2007.

Solomon, S., Qin, D., Manning, M., Alley, R., Berntsen, T., Bindoff, N., Chen, Z., Chidthaisong, A., Gregory, J., Hegerl, G., Heimann, M., Hewitson, B., Hoskins, B., Joos, F., Jouzel, J., Kattsov, V., Lohmann, U., Matsuno, T., Molina, M., Nicholls, N., J.Overpeck, Raga, G., Ramaswamy, V., Ren, J., Rusticucci, M., Somerville, R., Stocker, T., Whetton, P., Wood, R. A., and Wratt, D.: Climate Change 2007 - The Physical Science Basis, Contribution of Working Group I to the Fourth Assessment Report of the Intergovernmental Panel on Climate Change, Technical Summary, Cambridge University Press, Cambridge, United Kingdom and New York, NY, USA, 2007. 
Stephens, E. R.: The formation, reactions, and properties of peroxyacyl nitrates (PANS) in photochemical air pollution, Adv. Environ. Sci., 1, 119-147, 1969.

Stohl, A.: A 1-year Lagrangian "climatology" of airstreams in the Northern Hemisphere troposphere and lowermost stratosphere, J. Geophys. Res., 106, 7263-7279, doi:10.1029/2000JD900570, 2001.

Tikhonov, A. N. and Arsenin, V. Y.: Solutions of Ill-Posed Problems, Winston, Washington DC, USA, 1977.

Ungermann, J.: Improving retrieval quality for airborne limb sounders by horizontal regularisation, Atmos. Meas. Tech., 6, 15-32, doi:10.5194/amt-6-15-2013, 2013.

Ungermann, J., Kaufmann, M., Hoffmann, L., Preusse, P., Oelhaf, H., Friedl-Vallon, F., and Riese, M.: Towards a 3-D tomographic retrieval for the air-borne limb-imager GLORIA, Atmos. Meas. Tech., 3, 1647-1665, doi:10.5194/amt-3-1647-2010, 2010.

Ungermann, J., Blank, J., Lotz, J., Leppkes, K., Hoffmann, L., Guggenmoser, T., Kaufmann, M., Preusse, P., Naumann, U., and Riese, M.: A 3-D tomographic retrieval approach with advection compensation for the air-borne limb-imager GLORIA, Atmos. Meas. Tech., 4, 2509-2529, doi:10.5194/amt-4-2509-2011, 2011.

Ungermann, J., Kalicinsky, C., Olschewski, F., Knieling, P., Hoffmann, L., Blank, J., Woiwode, W., Oelhaf, H., Hösen, E., Volk, C. M., Ulanovsky, A., Ravegnani, F., Weigel, K., Stroh, F., and Riese, M.: CRISTA-NF measurements with unprecedented vertical resolution during the RECONCILE aircraft campaign, Atmos. Meas. Tech., 5, 1173-1191, doi:10.5194/amt-5-11732012, 2012.
Weigel, K., Hoffmann, L., Günther, G., Khosrawi, F., Olschewski, F., Preusse, P., Spang, R., Stroh, F., and Riese, M.: A stratospheric intrusion at the subtropical jet over the Mediterranean Sea: air-borne remote sensing observations and model results, Atmos. Chem. Phys., 12, 8423-8438, doi:10.5194/acp12-8423-2012, 2012.

WMO: Meteorology - a three-dimensional science: second session for the commission for aerology, WMO Bull., 6, 134-138, 1957.

WMO: Scientific Assessment of Ozone Depletion: 2002, Global Ozone Research and Monitoring Project, Report No. 47, Geneva, Switzerland, 2003.

Wunderli, S. and Gehrig, R.: Influence of temperature on formation and stability of surface PAN and ozone, a two year field study in Switzerland, Atmos. Environ., 25, 1599-1608, doi:10.1016/0960-1686(91)90018-3, 1991.

Zhang, F.: Generation of mesoscale gravity waves in uppertropospheric jet-front systems, J. Atmos. Sci., 61, 440-457, doi:10.1175/1520-0469(2004)061<0440:GOMGWI>2.0.CO;2, 2004. 